\title{
Modeling and measurements of urban aerosol processes on the neighborhood scale in Rotterdam, Oslo and Helsinki
}

\author{
Matthias Karl $^{1}$, Jaakko Kukkonen ${ }^{2}$, Menno P. Keuken ${ }^{3}$, Susanne Lützenkirchen ${ }^{4}$, Liisa Pirjola ${ }^{5,6}$, and \\ Tareq Hussein ${ }^{6,7}$ \\ ${ }^{1}$ Helmholtz-Zentrum Geesthacht, Institute of Coastal Research, Geesthacht, Germany \\ ${ }^{2}$ Atmospheric Composition, Finnish Meteorological Institute, Helsinki, Finland \\ ${ }^{3}$ TNO, Netherlands Organization for Applied Research, Utrecht, the Netherlands \\ ${ }^{4}$ City of Oslo - Agency for Urban Environment, Oslo, Norway \\ ${ }^{5}$ Department of Technology, Metropolia University of Applied Sciences, Helsinki, Finland \\ ${ }^{6}$ University of Helsinki, Department of Physics, P.O. Box 64, 00014 UHEL, Helsinki, Finland \\ ${ }^{7}$ The University of Jordan, Department of Physics, Amman 11942, Jordan \\ Correspondence to: Matthias Karl (matthias.karl@hzg.de)
}

Received: 4 November 2015 - Published in Atmos. Chem. Phys. Discuss.: 15 December 2015 Revised: 23 March 2016 - Accepted: 1 April 2016 - Published: 19 April 2016

\begin{abstract}
This study evaluates the influence of aerosol processes on the particle number (PN) concentrations in three major European cities on the temporal scale of $1 \mathrm{~h}$, i.e., on the neighborhood and city scales. We have used selected measured data of particle size distributions from previous campaigns in the cities of Helsinki, Oslo and Rotterdam. The aerosol transformation processes were evaluated using the aerosol dynamics model MAFOR, combined with a simplified treatment of roadside and urban atmospheric dispersion. We have compared the model predictions of particle number size distributions with the measured data, and conducted sensitivity analyses regarding the influence of various model input variables. We also present a simplified parameterization for aerosol processes, which is based on the more complex aerosol process computations; this simple model can easily be implemented to both Gaussian and Eulerian urban dispersion models. Aerosol processes considered in this study were (i) the coagulation of particles, (ii) the condensation and evaporation of two organic vapors, and (iii) dry deposition. The chemical transformation of gas-phase compounds was not taken into account. By choosing concentrations and particle size distributions at roadside as starting point of the computations, nucleation of gas-phase vapors from the exhaust has been regarded as post tail-pipe emission, avoiding the need to include nucleation in the process analysis.
\end{abstract}

Dry deposition and coagulation of particles were identified to be the most important aerosol dynamic processes that control the evolution and removal of particles. The error of the contribution from dry deposition to PN losses due to the uncertainty of measured deposition velocities ranges from -76 to $+64 \%$. The removal of nanoparticles by coagulation enhanced considerably when considering the fractal nature of soot aggregates and the combined effect of van der Waals and viscous interactions. The effect of condensation and evaporation of organic vapors emitted by vehicles on particle numbers and on particle size distributions was examined. Under inefficient dispersion conditions, the model predicts that condensational growth contributes to the evolution of PN from roadside to the neighborhood scale. The simplified parameterization of aerosol processes predicts the change in particle number concentrations between roadside and urban background within $10 \%$ of that predicted by the fully size-resolved MAFOR model. 


\section{Introduction}

Motor vehicle exhaust emissions constitute the major source of ultrafine particle (UFP, $<100 \mathrm{~nm}$ in aerodynamic diameter) pollution in urban environments (Harrison et al., 2011; Morawska et al., 2008; Pey et al., 2009; Johansson et al., 2007). Ultrafine particles can contain toxic contaminants, such as transition metals, polycyclic aromatic hydrocarbons (PAHs), and other particle-bound organic compounds, which may be responsible for initiating local lung damage, when the particles deposit on the epithelial surfaces (Lighty et al., 2000). Biodistribution studies suggest translocations of UFP from the respiratory system to other organs including liver, heart and the central nervous system, in which they can cause adverse health effects (Oberdörster et al., 2005; Kleinman et al., 2008; Kreyling et al., 2013).

In urban environments, ultrafine particles make the most significant contribution to total particle number (PN) concentrations, but only a small contribution to particulate matter (PM) mass. Hence, reliable information on the number concentrations, together with the size distributions, is needed to better assess the health effects of urban particulate pollution.

The exposure of the population in urban areas to particles may be assessed by modeling the spatial distribution of particles emitted from road transport and other sources in various micro-environments (e.g., Soares et al., 2014). Kumar et al. (2011) reviewed aerosol process modeling on urban and smaller scales. Aerosol dynamic models (i.e., process models of aerosol microphysics, often employing Lagrangian approaches to the fluid flow) have been used to model the spatial and temporal evolution of ultrafine particles in the initial vehicle exhaust plume during the first seconds after emission (e.g. Vignati et al., 1999; Pohjola et al., 2003, 2007). These models can be used to study the further evolution of the plume, if they will be coupled to an urban dispersion model. Particles emitted from road transport, as they are transported from the emission sources, are subject to complex dilution processes (turbulence generated by moving traffic, atmospheric turbulence) and transformation processes (nucleation, coagulation, condensation, evaporation, deposition, and heterogeneous chemical reactions), acting on different timescales. Aerosol dynamic processes continuously change the number and size distribution, after the particles have been released into air.

Clearly, dilution is an important process influencing PN concentrations and the spatial distributions in cities (e.g. Zhang et al., 2004; Pohjola et al., 2007; Keuken et al., 2012). An exhaust parcel emitted from the tailpipe of a vehicle first experiences fast dilution by the strong turbulence generated by moving traffic between tailpipe to roadside (Rao et al., 2002; Zhang and Wexler, 2004). On the neighborhood scale in the city, the parcel of exhaust is advected through a network of streets, over and around several buildings. On the city scale, the pollutant plume can extend vertically up to twice the average building height above the city's surface layer, and its dispersion becomes independent of the specific effects of individual buildings (Kumar et al., 2011).

The main aims of the present study are (i) the quantification of the impacts of relevant aerosol processes on the neighborhood and city scales and (ii) the derivation of a reasonably accurate, simplified parameterization of the most important aerosol processes, to be used in urban air quality models. The study is part of the European Union funded research project TRANSPHORM (Transport related Air Pollution and Health impacts - Integrated Methodologies for Assessing Particulate Matter). A related paper by Kukkonen et al. (2016) presents atmospheric dispersion modeling of particle number concentrations in the five target cities of the TRANSPHORM project, as well as on a European scale, and evaluates the predicted results against available measured concentrations. In the present model study, we have used the results of measurements from a campaign in Rotterdam, initiated by the TRANSPHORM project, and those from previous campaigns in Helsinki and Oslo. Our aims are to quantify the influence of selected individual aerosol processes for each measurement campaign and to inter-compare the relative contribution of the processes to $\mathrm{PN}$ changes in the selected campaigns and cities.

\section{Materials and methods}

\subsection{Aerosol process model MAFOR}

In order to study the relevance of aerosol dynamics on the fate of PN emitted from traffic in urban areas, the evolution of the particle size distribution with increasing distance from the roadside was modeled using the multicomponent aerosol dynamics model MAFOR (Karl et al., 2011). MAFOR uses a fixed sectional grid to represent the particle size distribution with size bins evenly distributed on a logarithmic scale. MAFOR has been evaluated against laboratory chamber data (Karl et al., 2012) and PN measurements at a motorway (Keuken et al., 2012); it has also been shown to compare well with the sectional aerosol dynamics model AEROFOR (Pirjola and Kulmala, 2001).

Aerosol processes considered in this study were condensation and evaporation of organic vapors, coagulation of particles due to Brownian motion, and dry deposition (particle deposition in contact with the street surface and other urban structures). In this study 120 size bins were used in the MAFOR model, to represent the aerosol size distribution ranging from particle diameters from $1 \mathrm{~nm}$ to $1 \mu \mathrm{m}$.

In the default configuration of the model, particles were assumed to be spherical and the enhancement of coagulation by van der Waals forces and viscous interactions was not taken into account. Additional sensitivity tests were performed to study the respective effects of fractal geometry and of van der Waals forces combined with viscous interactions on the model results. Further, effects of turbulent shear on 
coagulation between exhaust particles can be neglected for the timescale from roadside to ambient (Zhang and Wexler, 2004).

The various aerosol dynamical processes were treated by calculation of the temporal variation of the particle number concentration and the mass concentrations of each chemical component within each size section. Mass transfer of gas molecules to particles was calculated using the Analytical Predictor of Condensation scheme (Jacobson, 1997).

Dry deposition of particles was modeled according to Kouznetsov and Sofiev (2012), which accounts for the physical properties of both the air flow and the surface, as well as the physical properties of the particle size. In this approach rough surfaces are characterized by two length scales: the aerodynamic roughness and the so-called collection scale, which incorporates the effective size of collectors and a ratio of the airflow velocity at the top of the roughness elements to the friction velocity. Alternatively, MAFOR provides a treatment to calculate size-dependent deposition rates according to Schack Jr. et al. (1985) and Hussein et al. (2012).

The concept regarding condensation and evaporation between roadside and ambient environment applied in this study is based on the work of Zhang and Wexler (Zhang and Wexler, 2004; Zhang et al., 2004). The effective behavior of condensable organic vapors from vehicular exhaust with respect to changes of the particle number concentration and the particle size distribution was modeled by introducing two different volatility classes: the n-alkane $\mathrm{C}_{22} \mathrm{H}_{46}$ (abbreviated as $\mathrm{C} 22$ ) representing semi-volatile vapors and the n-alkane $\mathrm{C}_{28} \mathrm{H}_{58}$ (abbreviated as $\mathrm{C} 28$ ) representing low-volatile vapors. Both organic compounds can condense or evaporate to or from particles during their transport downwind from the road. Vapor pressure of n-alkanes as function of temperature was adopted from the work by Lemmon and Goodwin (2000).

Carbonaceous aerosol in MAFOR is separated into (i) elemental carbon $\left(\mathrm{EC}_{\mathrm{p}}\right)$ from primary emissions, treated as a non-volatile substance, and (ii) organic carbon $\left(\mathrm{OC}_{\mathrm{p}}\right)$, treated as a volatile substance. In this study, organic carbon is assumed to be composed of organic acid (for background $\mathrm{OC}_{\mathrm{p}}$ ) and the two n-alkanes (originated from vehicles). The organic fraction in the nucleation mode below $10 \mathrm{~nm}$ diameter was composed by $100 \%$ of $\mathrm{C} 28$ in the roadside aerosol. A density of $1200 \mathrm{~kg} \mathrm{~m}^{-3}$ (Virtanen et al., 2002) was used for $\mathrm{EC}_{\mathrm{p}}$. The density of $\mathrm{OC}_{\mathrm{p}}$ was calculated as the weighted average of the densities of the organic compounds.

\subsection{Modeling of the dilution of exhausts}

MAFOR is a one-dimensional model with downwind distance as spatial dimension; it is therefore necessary to couple it to a dispersion model, to simulate combined atmospheric dispersion and transformation processes. In order to approximate atmospheric dispersion, we used a simplified treatment of dilution of particle numbers. This procedure implies the

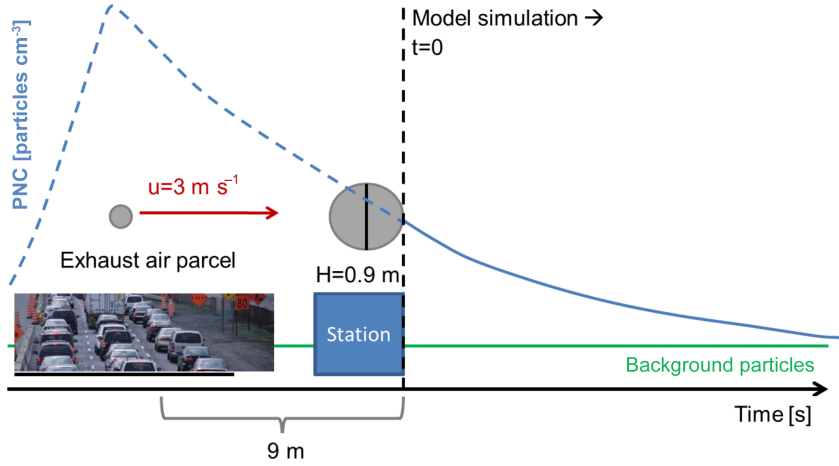

Figure 1. Idealized scenario for model simulations with MAFOR to study aerosol processes between roadside and neighborhood scale. Model simulations start at the point where the exhaust parcel (plume height typically $0.9 \mathrm{~m}$ ) has approached the roadside traffic station. The simulations are initialized with PN concentration and size distribution measured at roadside. Particle concentrations in the exhaust air are diluted by background air with constant PN concentration.

assumption of a well-mixed state within each cross-wind cross-section of the plume. The assumption of a well-mixed state may overestimate the influence of the processes responsible for the temporal decrease of the PN, due to the nonlinear nature of the involved processes (condensation and coagulation). Model runs were performed with different dispersion conditions to address the influence of aerosol processes for a wide range of meteorological dispersion regimes.

Emissions from traffic sources commonly contribute to particle size distributions with distinct modes, i.e., nucleation, Aitken, accumulation, and coarse mode. Formation of new liquid particles in the exhaust by nucleation of gases, such as sulfuric acid and semi-volatile organic substances, occurs during the first milliseconds (Kittelson, 1998) after release of the exhaust into the ambient air. On-road measurements by Rönkkö et al. (2007) confirmed that the nucleation mode was already present after $0.7 \mathrm{~s}$ residence time in the atmosphere. Thus, it is practical to regard nucleation as a process that has already occurred, when one considers roadside concentrations. The evolution of vehicular emissions from the engine to the roadside concentrations was not considered in this study, as we used the particle size distributions measured at the roadside locations as a starting point.

Idealized scenarios were set up for the study of relevant aerosol processes (i.e., the dry deposition, the growth by condensation of gases and the coagulation of particles) and dilution by background air (see Fig. 1).

We used a simple horizontal particle dilution parameterization, following the numerical power function $y=a \times$ $x^{-b}=a \times(U t)^{-b}$, where $x$ (in $\mathrm{m}$ ) is the distance from the roadside and $U$ is the horizontal wind speed perpendicular to the road. The height of the air parcel (plume height), $H_{m}$ (in $\mathrm{m})$, containing the exhaust emissions, as function of time $t$ 
(in s) during its travel away from the roadside at a specific wind speed was defined by

$H_{m}(t)=\sqrt{H_{m, 0}^{2}+\left(a \times\left(10^{-3} \times U t\right)^{b}\right)^{2}}$,

where $H_{m, 0}$ is the initial plume (or air parcel) height at the roadside. The particle dilution rate for use in the aerosol model was obtained by derivation of the above mentioned numerical power function as function of time. The change of particle number concentration, $N$ (in particles $\mathrm{cm}^{-3}$ ), in size section $i$ due to dilution with background air is

$$
\left.\frac{\mathrm{d} N_{i}}{\mathrm{~d} t}\right|_{\text {dilution }}=-\frac{b}{t}\left(N_{i}-N_{\mathrm{bg}, i}\right),
$$

where $N_{\mathrm{bg}, i}$ is the number concentration of background particles in the same size bin. No additional emissions of particles or vapors are collected during transport from roadside to ambient in this idealized scenario.

Dilution parameters $a$ and $b$ that are used in Eqs. (1) and (2) for moderate dispersion conditions were derived from a fit of the modeled total number concentration to measured number concentration in different distances (below $100 \mathrm{~m}$ ) from a major highway in Helsinki (LIPIKA campaign, case 10; Fig. 5 in Pohjola et al., 2007). It was assured that the PN change in the distance up to $100 \mathrm{~m}$ was solely due to dilution with background air. Best fit was obtained with parameter values $a=40$ and $b=0.5$. For neutral conditions, the values $a=86.49$ and $b=0.923$ were reported for dispersion downwind of a motorway (Petersen, 1980). Similar values were adopted for efficient dispersion conditions in this study ( $a=80.0$ and $b=0.90)$. For inefficient dispersion conditions, $a$ and $b$ were chosen to be typical for atmospheric situations with inversion and stagnant air. Details on the approximation of initial plume height, $H_{m, 0}$, at the roadside are provided in Sect. S1 of the Supplement. Table 1 provides an overview of the set of meteorological and dilution parameters that were tested in sensitivity studies. Model simulations were forced by the applied dilution scheme to relax towards the size-binned particle concentrations of the background air, where the time constant of the relaxation was controlled by the respective dilution parameters.

The model simulations were started by assuming an initial chemical composition of the aerosol at the respective roadside traffic site and urban background site. Chemical composition of the urban background aerosol was estimated based on the measured $\mathrm{PM}_{2.5}$ and the mass fractions of the chemical components in $\mathrm{PM}_{2.5}$. Composition of the nucleation, Aitken, accumulation and coarse modes was estimated based on mass fractions for the urban background of Helsinki (Pohjola et al., 2007). Then mass concentrations of the respective lognormal modes were distributed over the discrete size sections of the model. The aerosol composition of the trafficinfluenced aerosol at the traffic station was approximated by adding mass concentrations of $\mathrm{OC}_{\mathrm{p}}$ and $\mathrm{EC}_{\mathrm{p}}$ (from vehicle exhaust emissions) to the mass concentrations of the background aerosol. Fixed modal $\mathrm{OC}_{\mathrm{p}}: \mathrm{EC}_{\mathrm{p}}$ ratios were used (nucleation mode: $100: 0$, Aitken mode: $80: 20$, accumulation mode 1: $40: 60$, accumulation mode $2: 60: 40$ ) based on the mass composition of vehicle exhaust particle emissions (Pohjola et al., 2007). Finally, the initial model number size distribution was fitted to the observed number size distribution at the traffic site for each of the campaigns, by variation of the geometric-mean mass diameter (by $\pm 30 \%$ ) and the geometric standard deviation (within the range 1.5-2.0) in each lognormal mode.

The applied aerosol dynamics model makes no assumption regarding the equilibrium between organic vapor and the condensed phase at the roadside. If the gas-phase concentration of an organic compound is below the saturation concentration, the compound will evaporate from the particles, if it is above the saturation concentration, the compound will condense to the particles. During the road-to-ambient process, some compounds may continue condensing, while others begin evaporating, depending on the relative magnitude of their vapor pressures. In addition, the vapor pressure of the model compounds $\mathrm{C} 22$ and $\mathrm{C} 28$ is further modified by their molar fraction in the particle phase, according to Raoult's law, and by their molar volume and surface tension according to the Kelvin effect.

For the included campaigns, gas-phase concentration of n-alkanes and other condensable organic compounds have not been measured at the roadside locations. Measurements of n-alkane vapor concentrations in urban environments indicate typical concentrations of $5 \mathrm{ppt}$ for the sum of the nalkanes, but higher concentrations may occur (for more details see Sect. S2). Pohjola et al. (2007) obtained best fit between modeled and measured particle size distribution on a distance scale of $125 \mathrm{~m}$ near a major road in Helsinki when using roadside concentrations of one condensable organic vapor of the order of $10^{10}$ molecules $\mathrm{cm}^{-3}$ (ca. $0.4 \mathrm{ppb}$ ). Based on this, initial concentrations of $0.25 \mathrm{ppb} \mathrm{C} 22$ and $0.25 \mathrm{ppb}$ C28 were used in the reference case (all campaigns and dispersion conditions). The background concentration of $\mathrm{C} 22$ and C28 was set to zero, forcing maximum dilution of the condensable organic vapors during travel of the air parcel away from the roadside.

Additional sensitivity tests were carried out to address uncertainties in the modeling with respect to (i) dry deposition of particles to urban surfaces, (ii) assumptions about the roadside concentrations of condensable organic vapors (represented as n-alkanes), (iii) the fractal geometry of soot particles and (iv) the enhancement of coagulation through van der Waals and viscous forces.

\subsection{The effect of different surface types on the dry deposition of particles}

As the air parcel containing vehicle exhaust leaves street scale, it can be assumed to be advected through a network of 
Table 1. Meteorological and dilution parameters used in the numerical computations on the evolution of the particle size distribution and PN between roadside and neighborhood timescales. Notation: $U=$ wind speed at a height of $10 \mathrm{~m}, H_{m}=$ initial plume height at the roadside station, $a, b=$ parameters of the particle dilution parameterization $\left(y=a \times x^{-b}\right.$, where $x$ is the distance from roadside in meters). The moderate dispersion conditions were used for the reference case.

\begin{tabular}{lcccc}
\hline Dispersion cases & Wind speed & Initial plume & \multicolumn{2}{c}{ Dilution parameter } \\
\cline { 4 - 5 } & $U\left(\mathrm{~m} \mathrm{~s}^{-1}\right)$ & $H_{m, 0}(\mathrm{~m})$ & $a$ & $b$ \\
\hline Moderate dispersion & 3.0 & 0.9 & 40.0 & 0.5 \\
Efficient dispersion & 4.0 & 0.7 & 80.0 & 0.9 \\
Inefficient dispersion & 1.0 & 2.6 & 20.0 & 0.2 \\
\hline
\end{tabular}

streets, and over and around buildings, defined as the neighborhood scale with a characteristic length scale of $1-2 \mathrm{~km}$. On the neighborhood scale, geometrical features dominate mean flow and mixing. Effects caused by buildings and other structures are disregarded in this study. Instead the flow was assumed to have a long fetch over a statistically homogeneous surface. However, different average surface types may have an impact on dry deposition of particles. In a series of tests the sensitivity of PN changes were studied, caused by dry deposition on various surface types and roughness conditions. Table 2 provides a summary of relevant parameters for dry deposition used in the reference case (all campaigns and dispersion conditions) and in the sensitivity tests (selected campaigns).

The parameterization used in the reference runs is thought to represent dry deposition to typical urban surfaces, i.e. streets and buildings (urban case). Values for friction velocity near surface, $u^{*}$, and roughness height, $z_{0}$, used in the urban case were adopted from the work of Ketzel and Berkowicz (2004). Sensitivity tests for dry deposition were performed for the campaigns in Rotterdam and Oslo using the dilution parameters for moderate dispersion conditions.

The methodology by Kouznetsov and Sofiev (2012) considers Brownian diffusion, interception, inertial impaction and gravitational settling as mechanisms for dry deposition to rough surfaces. They define a collection length scale to characterize the properties of rough surfaces. This collection length depends on the ratio $U_{\text {top }} / u^{*}$ ( $U_{\text {top }}$ is the wind speed at top of the canopy, i.e. at height $z_{\mathrm{C}}$ ) and to the effective collector size, $d_{\mathrm{col}}$, of the canopy. The methodology by Hussein et al. (2012) is a three-layer deposition model formulation with Brownian and turbulent diffusion, turbophoresis and gravitational settling as the main particle transport mechanisms to rough surfaces. Hussein et al. (2012) introduced the effective surface roughness length $F^{+}$to relate roughness height and the peak-to-peak distance between its roughness elements. For a hydraulically smooth surface, $F^{+}$ approaches zero. Parameters $z_{0}, z_{\mathrm{C}}$ and $d_{\mathrm{col}}$ are only used in the concept of Kouznetsov and Sofiev (2012) while $F^{+}$ is only used in the concept of Hussein et al. (2012). Sizedependent dry deposition velocities of particles were calculated with two different methodologies: the methodology

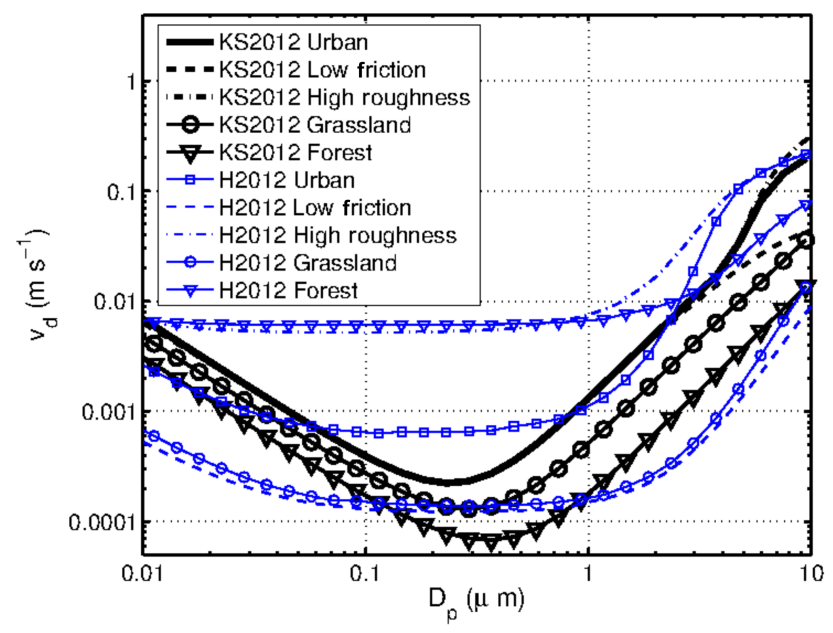

Figure 2. Dry deposition velocity, $v_{\mathrm{d}}$ (in $\mathrm{ms}^{-1}$ ) as function of particle diameter $D_{\mathrm{p}}$ (in $\left.\mu \mathrm{m}\right)$, using a particle density of $1400 \mathrm{~kg} \mathrm{~m}^{-3}$. The results with the model of Kouznetsov and Sofiev (2012) (KS2012) are shown as black lines and the results with the model of Hussein et al. (2012) (H2012) are shown as blue lines. The curve of "KS2012 Urban" (thick black line) represents the dry deposition parameterization that is used in all model runs with MAFOR. The curves for cases "KS2012 Low Friction" (dashed black line) and "KS2012 High Roughness" (dash-dotted black line) partly overlay with the curve for "KS2012 Urban".

of Kouznetsov and Sofiev (2012) (short: KS2012) was applied in the reference case for all simulations. In addition the methodology of Hussein et al., 2012 (short: H2012) was applied for all cases in the sensitivity test.

Figure 2 shows size-dependent dry deposition velocity of particles for the different cases listed in Table 2 for the two methodologies. The curve "KS2012 Urban" (thick black line) represents the parameterization used in the reference runs of this study. Dry deposition velocities calculated by H2012 for the urban case ("H2012 Urban") agree with "KS2012 Urban" within a factor of 3 as a function of particle diameter. Results from the KS2012 methodology were not sensitive to changes of friction velocity within a range $\left(0.27-1.33 \mathrm{~m} \mathrm{~s}^{-1}\right)$ typical for the urban environment. 
Table 2. Dry deposition of particles to urban surfaces. Parameter values used in the modelling of the reference case (all campaigns) and in the sensitivity cases for the dry deposition process. Notation: $u^{*}=$ friction velocity, $z_{0}=$ roughness height, $d_{\text {col }}=$ effective collector size, $z_{\mathrm{C}}=$ canopy height, $F^{+}=$effective roughness length. Values for $F^{+}$were adopted from Hussein et al. (2012) for corresponding surface and vegetation types.

\begin{tabular}{llrrrrr}
\hline Case & Surface type & $\begin{array}{r}u^{*} \\
\left(\mathrm{~cm} \mathrm{~s}^{-1}\right)\end{array}$ & $\begin{array}{c}z_{0} \\
(\mathrm{~m})\end{array}$ & $\begin{array}{c}d_{\mathrm{col}} \\
(\mathrm{cm})\end{array}$ & $\begin{array}{c}z_{\mathrm{C}} \\
(\mathrm{m})\end{array}$ & $\begin{array}{c}F^{+} \\
(-)\end{array}$ \\
\hline Urban & Street and building & 133 & 0.13 & 0.20 & 10.0 & 0.55 \\
Low friction & Street and building & 27 & 0.13 & 0.20 & 10.0 & 0.55 \\
High roughness & Street and building & 133 & 1.00 & 0.20 & 10.0 & 1.60 \\
Green area without trees & Grassland & 36 & 0.01 & 0.40 & 0.20 & 0.50 \\
Green area with forest & Deciduous forest & 75 & 1.00 & 1.00 & 12.0 & 2.25 \\
\hline
\end{tabular}

A large discrepancy between the two methodologies was found for deciduous forest (green area with forest). H2012 closely matches measured dry deposition velocities over a beech forest by Pryor (2006) when using $F^{+}=2.25$. Kouznetsov and Sofiev (2012) state that their parameterization offsets measured data for broad-leaf forests by 2-3 orders, unless using a very small collector size $\left(d_{\text {col }}<0.2 \mathrm{~cm}\right)$. However, their parameterization is in close agreement with one wind tunnel measurement for $1 \mu \mathrm{m}$ particle deposition on natural oak branches by Reinap et al. (2009). It should be kept in mind that "KS2012 Forest" does not necessarily represent realistic dry deposition rates to forests and was rather included as lower limit for particle deposition from the KS2012 method in urban environments.

\subsection{Experimental data from the measurement campaigns}

We have used the measured particle number size distributions at a traffic station and at an urban background (UB) station, during campaigns in the cities of Oslo, Rotterdam and Helsinki. The included campaign data sets were the following:

1. Rotterdam 2011, TRANSPHORM. Traffic site Bentinckplein and urban background location Zwartewaalstraat (6-19 May 2011) at Rotterdam, and the regional background station at Cabauw in the Netherlands (February-November 2011).

2. Oslo 2008, UFP-Oslo. Traffic site Smestad and urban background location Sofienberg park (12 December 2007 to 17 April 2008).

3. Helsinki, SAPPHIRE case I. Traffic site at Herttoniemi and urban background location at Kumpula, Helsinki, 23-28 August 2003 (Hussein et al., 2007).

4. Helsinki, SAPPHIRE case II. Traffic site at Herttoniemi and urban background location at Kumpula, Helsinki, 9-11 February 2004 (Hussein et al., 2007).
5. Helsinki LIPIKA. Traffic site at Herttoniemi and urban background location at Saunalahti bay, Helsinki, 1720 February 2003 (Pirjola et al., 2006; Pohjola et al., 2007).

6. Helsinki, MMEA. Traffic site at Mannerheimintie and urban background location at Lääkärinkatu, Helsinki, 13-14 December 2010 (Pirjola et al., 2012).

The measured data for roadside and urban background in the TRANSPHORM campaign at Rotterdam, in the UFPOslo ("Measurements of ultrafine particles in Oslo") campaign at Oslo, and in the SAPPHIRE campaigns in Helsinki were obtained simultaneously. Whereas in the LIPIKA and the MMEA campaigns in Helsinki the measured data were obtained with the mobile laboratory "Sniffer" (e.g., Pirjola et al., 2004) at various locations during each measurement day. Quality control (QC) procedures in the measurement campaigns at Helsinki are described in the cited literature. Table 3 compiles the information on the size distribution data from the different campaigns in Rotterdam, Oslo, and Helsinki. In order to obtain an average size distribution for the respective traffic station and urban background station, either median or mean of measured time series of size distributions $\left(\mathrm{d} N / \mathrm{d} \log \left(D_{\mathrm{p}}\right)\right)$ were calculated, as specified in Table 3 . A comparison of measured total PN concentrations between campaigns is shown in Supplement Fig. S1.

In Rotterdam, particle measurements were performed at the regional background station at Cabauw near Rotterdam and a traffic location at less than $5 \mathrm{~m}$ from the roadside (Bentinckplein) by two scanning mobility particle sizer (SMPS) instruments: one SMPS 3080 covering size diameters $\left(D_{\mathrm{p}}\right) 10-480 \mathrm{~nm}$ and a CPC 3775 (TSI Inc.) with a $50 \%$ cut-off at $4 \mathrm{~nm}$, and one SMPS 3034 with $D_{\mathrm{p}} 10-470 \mathrm{~nm}$ and a CPC 3010 (TSI Inc.) with a $50 \%$ cut-off at $7 \mathrm{~nm}$. The comparability of both SMPS was tested by parallel measurements. The Pearson correlation $(r)$ between the parallel SMPS measurements was 0.96 , hence $R^{2}=0.92$. The absolute mean bias was 5400 particle $\mathrm{cm}^{-3}$ between both instruments, corresponding to a relative bias of $16 \%$. The results of the PNC measurements were corrected for the difference in comparability between both instruments. Hourly av- 
Table 3. Campaign number size distribution data used in this study. Notation: RT $=$ roadside traffic site, $\mathrm{ST}=$ street canyon traffic site, $\mathrm{UB}=$ urban background, $\mathrm{RB}=$ regional background.

\begin{tabular}{|c|c|c|c|c|c|c|c|}
\hline City & $\begin{array}{l}\text { Campaign/ } \\
\text { case }\end{array}$ & $\begin{array}{l}\text { Time } \\
\text { period }\end{array}$ & $\begin{array}{l}\text { Classification } \\
\text { of location }\end{array}$ & Name of station & $\begin{array}{l}\text { Average total PN } \\
\left(\text { particles } \mathrm{cm}^{-3} \text { ) }\right.\end{array}$ & $\begin{array}{l}\text { Data averaging } \\
\text { method }\end{array}$ & References \\
\hline Rotterdam & TRANSPHORM & 6-19 May 2011 & Suburban & $\begin{array}{l}\text { Bentickplein (ST) } \\
\text { Zwartewaalstraat (UB) } \\
\text { Cabauw (RB) }\end{array}$ & $\begin{array}{l}20300 \\
14100 \\
10200^{1}\end{array}$ & $\begin{array}{l}\text { Mean } \\
\mathrm{d} N / \mathrm{d} \log \left(D_{\mathrm{p}}\right)\end{array}$ & This Study \\
\hline Oslo & UFP-Oslo & $\begin{array}{l}12 \text { Dec } 2007 \\
- \\
17 \text { Apr } 2008\end{array}$ & Suburban & $\begin{array}{l}\text { Smestad (RT) } \\
\text { Sofienberg park (UB) }\end{array}$ & $\begin{array}{l}24000 \\
9300\end{array}$ & $\begin{array}{l}\text { Mean } \\
\mathrm{d} N / \mathrm{d} \log \left(D_{\mathrm{p}}\right)^{2}\end{array}$ & This Study \\
\hline \multirow[t]{2}{*}{ Helsinki } & \multirow[t]{2}{*}{ SAPPHIRE case I } & \multirow[t]{2}{*}{ 23-28 Aug 2003} & \multirow[t]{2}{*}{ Suburban } & $\begin{array}{l}\text { Highway Itäväylä, } \\
\text { Herttoniemi (RT) } \\
\text { at } 65 \text { m distance }\end{array}$ & 32000 & \multirow[t]{2}{*}{$\begin{array}{l}\text { Median } \\
\mathrm{d} N / \mathrm{d} \log \left(D_{\mathrm{p}}\right)^{3}\end{array}$} & \multirow[t]{2}{*}{ Hussein et al. (2007) } \\
\hline & & & & Kumpula (UB) & 7200 & & \\
\hline \multirow[t]{2}{*}{ Helsinki } & \multirow[t]{2}{*}{ SAPPHIRE case II } & \multirow[t]{2}{*}{ 9-11 Feb 2004} & \multirow[t]{2}{*}{ Suburban } & $\begin{array}{l}\text { Highway Itäväylä, } \\
\text { Herttoniemi (RT) } \\
\text { at } 65 \mathrm{~m} \text { distance }\end{array}$ & 55100 & \multirow[t]{2}{*}{$\begin{array}{l}\text { Median } \\
\mathrm{d} N / \mathrm{d} \log \left(D_{\mathrm{p}}\right)^{3}\end{array}$} & \multirow[t]{2}{*}{ Hussein et al. (2007) } \\
\hline & & & & Kumpula (UB) & 11300 & & \\
\hline \multirow[t]{2}{*}{ Helsinki } & \multirow[t]{2}{*}{ LIPIKA } & \multirow[t]{2}{*}{17 Feb 2003} & \multirow[t]{2}{*}{ Suburban } & $\begin{array}{l}\text { Highway Itäväylä, } \\
\text { Herttoniemi (RT) } \\
\text { at } 9 \mathrm{~m} \text { distance }\end{array}$ & 129600 & $\begin{array}{l}1 \text { data record } \\
(10 \mathrm{~min} \text { average })\end{array}$ & \multirow[t]{2}{*}{$\begin{array}{l}\text { Pirjola et al. (2006) } \\
\text { and Pohjola et al. (2007) }\end{array}$} \\
\hline & & & & $\begin{array}{l}\text { Saunalahti bay, } \\
\text { Herttoniemi (UB) }\end{array}$ & 13400 & $\begin{array}{l}\text { Mean } \\
\mathrm{d} N / \mathrm{d} \log \left(D_{\mathrm{p}}\right)\end{array}$ & \\
\hline \multirow[t]{2}{*}{ Helsinki } & \multirow[t]{2}{*}{ MMEA } & \multirow[t]{2}{*}{ 9-11 Feb 2004} & \multirow[t]{2}{*}{ Suburban } & $\begin{array}{l}\text { Mannerheimintie (ST), } \\
\text { Herttoniemi (RT) } \\
\text { at } 0 \mathrm{~m}(\text { or } 8 \mathrm{~m}) \text { distance }\end{array}$ & $\begin{array}{l}51000 \\
(25800)\end{array}$ & $\begin{array}{l}1 \text { data record } \\
(10 \mathrm{~min} \text { average })\end{array}$ & \multirow[t]{2}{*}{ Pirjola et al. (2012) } \\
\hline & & & & Lääkärinkatu (UB) & 13700 & $\begin{array}{l}\text { Mean } \\
\mathrm{d} N / \mathrm{d} \log \left(D_{\mathrm{p}}\right)\end{array}$ & \\
\hline
\end{tabular}

${ }^{1}$ Annual average (2011) at Cabauw. ${ }^{2}$ Weekdays, between 6 a.m. and 3 p.m. ${ }^{3}$ Excluding night-time between 10 p.m. to 6 a.m.

eraged wind direction was used to select campaign data that were directly influenced by the traffic emissions in the street. The traffic volume at Bentinckplein, which is a street canyon (width: $50 \mathrm{~m}$; height: $12 \mathrm{~m}$ ) was 35000 vehicles per $24 \mathrm{~h}$ with $4 \%$ trucks and buses. The urban background location Zwartewaalstraat in Rotterdam total PN concentrations were measured by a condensation particle counter (TSI 3007). The entire monitoring period at the regional background site was from February until December 2011. QC procedures were derived from the European Supersites for Atmospheric Aerosol Research (EUSAAR) project (Asmi et al., 2011). These involved inter-comparison studies of monitoring instruments, biweekly checking of the sampling flow and annual calibration of the PN monitors by the manufacturer.

In Oslo, PN concentration and particle size distributions were measured at two stations in the municipality of Oslo for a 4-month period in winter 2008, using a Grimm 565 Environmental Wide Range Aerosol Spectrometer system (http://www.GRIMM-Aerosol.com). This system combines a Grimm 190 aerosol spectrometer OPC (optical particle counter), and a scanning mobility particle sizer with a condensation particle counter (SMPS+C). The entire system in principle covers the range from $5 \mathrm{~nm}$ to $30 \mu \mathrm{m}$. Instruments were calibrated by the manufacturer prior to installation on site. Weekly zero filter test and other maintenance was carried out according to the manufacturers guide. In addition to automatic QC in the Grimm software, data from the two sites were compared and aligned with other air quality data from the respective sites. For the analysis of the Oslo campaign, only data from the SMPS were used and the smallest size bin was discarded. The traffic station (Smestad) was at a busy road with an average daily traffic (ADT) of around 50000 vehicles. The traffic signal at the urban background station (Sofienberg park) showed a continuous shift of the size distribution peak towards larger sizes with decreasing air temperature, i.e., the maximum of the size distribution is shifted from $16 \mathrm{~nm}$ at $6^{\circ} \mathrm{C}$ to $26 \mathrm{~nm}$ at $-10^{\circ} \mathrm{C}$. Size distribution data measured at -8 to $-12^{\circ} \mathrm{C}$ were used as a separate data set, UFP-Oslo Winter. The complete data set from the period December 2007 to April 2008 is referred to as UFP-Oslo Tav.

For Helsinki, two cases from the SAPPHIRE campaign, one case from the LIPIKA campaign (both at Herttoniemi), and one case at the city center from the MMEA campaign (Pirjola et al., 2012) were included. The roadside sta- 
tion near the highway Itäväylä at Herttoniemi is located about $6 \mathrm{~km}$ east of the center of Helsinki in a suburban area, with substantial local traffic. Particle measurements were performed with a differential mobility particle sizer (DMPS) at the background station and with a twin SMPS at the traffic site. Particle measurements during the LIPIKA campaign were conducted by Sniffer at various locations near the highway Itäväylä (Pirjola et al., 2006). The highway consists of six lanes, three lanes to both directions (total width of three lanes: $12 \mathrm{~m}$ ), and a $6 \mathrm{~m}$ wide central grass area between the lanes to both directions, with a speed limit of $80 \mathrm{~km} \mathrm{~h}^{-1}$. Particle size distributions in the range of $7 \mathrm{~nm}$ to $10 \mu \mathrm{m}$ (aerodynamic diameter) were measured by an electrical low-pressure impactor (ELPI, Dekati Ltd.; 12 channels). Nucleation mode particles were measured with high size resolution by a Hauke type SMPS (20 channels); measured size range was 3-50 nm (mobility diameter). The study period included 14 cases of measurements downwind of the highway Itäväylä from wind sector 1 (northwestern wind; Pirjola et al., 2006). The daily traffic density varied between 32000-54000 vehicles per day. Based on the traffic density information for the year 2001 , the vehicle fleet on the highway was composed of $85 \%$ light-duty vehicles (of which $11 \%$ were diesel), $12 \%$ vans (of which about $84 \%$ diesel), and $4 \%$ heavy-duty vehicles (Hussein et al., 2007).

During the MMEA campaign (Pirjola et al., 2012) the mobile laboratory "Sniffer" was driving along the main street Mannerheimintie (MA) at the city center of Helsinki. MA is about $40 \mathrm{~m}$ wide and surrounded by $21 \mathrm{~m}$ tall buildings at both sides. The daily traffic flow was 36300 vehicles day $^{-1}$ (of which ca. $10 \%$ were heavy duty diesel vehicles). On 1314 December 2010, the northeastern wind was perpendicular to MA, allowing traffic exhaust to be diluted freely between the buildings as in open environments. During rush hours, "Sniffer" was stopping around $10 \mathrm{~min}$ at 8, 28 and $56 \mathrm{~m}$ distances from the driving lane of MA downwind. Particle size distribution was measured by two SMPS (size ranges: 360 and $10-420 \mathrm{~nm}$ ). The urban background particles were measured while Sniffer was standing at Lääkärinkatu, $300 \mathrm{~m}$ north from the measurement sites at MA.

A summary of the meteorological and dispersion conditions for the different campaigns is given in Table S1 in the Supplement. Measured meteorological data were not directly used in the model study of idealized scenarios, but are considered to be important for discussing the relevance of aerosol dynamical processes compared to dilution under real-world conditions.

\section{Results}

\subsection{Traffic-related particle size distributions in the campaigns}

Measured PN concentrations based on hourly averages or 10 min averages (in case of the LIPIKA and MMEA campaigns) showed a wide range of PN concentrations (20000100000 particles $\mathrm{cm}^{-3}$ ) for the traffic sites considered, depending on the season of the year, traffic density, and distance from the road. Size distributions of the measured data sets at the traffic sites from all campaigns were normalized by the measured total PN concentrations (Fig. 3). We have also calculated the average values of the size distribution curves for all traffic sites, denoted as "mean of traffic sites" (black curve in Fig. 3). This size distribution is considered to be representative for the traffic-influenced roadside aerosol in the considered cities.

The "mean of traffic sites" distribution is characterized by a fraction of ultrafine particles $\left(D_{\mathrm{p}}: 10-100 \mathrm{~nm}\right)$ and accumulation mode (ACC) particles $\left(D_{\mathrm{p}}: 100-500 \mathrm{~nm}\right)$ of 80 and $4 \%$, respectively, while $16 \%$ of the particles were below $10 \mathrm{~nm}$. SAPPHIRE Case I had the highest fraction of $<$ $10 \mathrm{~nm}$ particles $(38 \%)$; in Rotterdam $<10 \mathrm{~nm}$ particles were not measured. For the other campaigns fraction of $<10 \mathrm{~nm}$ particles was in the range 6-19\%. The fraction of ultrafine particles was $60 \%$ for SAPPHIRE Case I and 74-87\% for all other campaigns. The fraction of ACC particles was smallest for the SAPPHIRE campaigns $(\approx 1 \%)$, and between 4 and $9 \%$ for the other campaigns in Helsinki and Oslo.

From a three-modal fit to the mean traffic-related size distribution with the MAFOR model (following the procedure described in Sect. 2.2), three distinct modes with mean diameter at 17,85 , and $250 \mathrm{~nm}$, respectively, were obtained. The measured average size distributions from the campaigns LIPIKA and MMEA in Helsinki, as well as UFP-Oslo Tav exhibited a similar shape as the mean traffic-related size distribution. The distribution of SAPPHIRE Case II also resembled the constructed distribution but did not show significant particle numbers with diameter $>100 \mathrm{~nm}$. Ultrafine particles measured at the traffic sites in the campaigns were most likely from fresh vehicle exhaust emissions. Particles emitted from diesel engines are usually in the size range 20$130 \mathrm{~nm}$ (e.g., Kittelson, 1998), somewhat larger than those emitted from gasoline engines, typically being in the range 20-60 nm (Harris and Maricq, 2001; Ristovski et al., 2006). Comparing campaigns in Helsinki, MMEA size distribution peaked at 20-40 nm, while LIPIKA and SAPPHIRE size distributions peaked at $8-25 \mathrm{~nm}$. The higher fraction of heavyduty diesel vehicles at Mannerheimintie (10\%) compared to highway Itäväylä (4\%) could be one possible reason for the peak at relatively larger sizes in MMEA. Different driving conditions may also have contributed to the difference in peaks; at Mannerheimintie rush hour limited the speed to 20- 
(a)

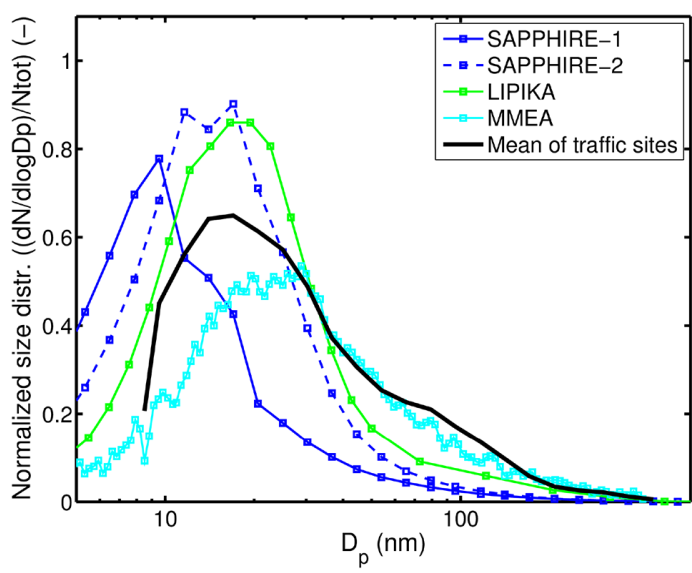

(b)

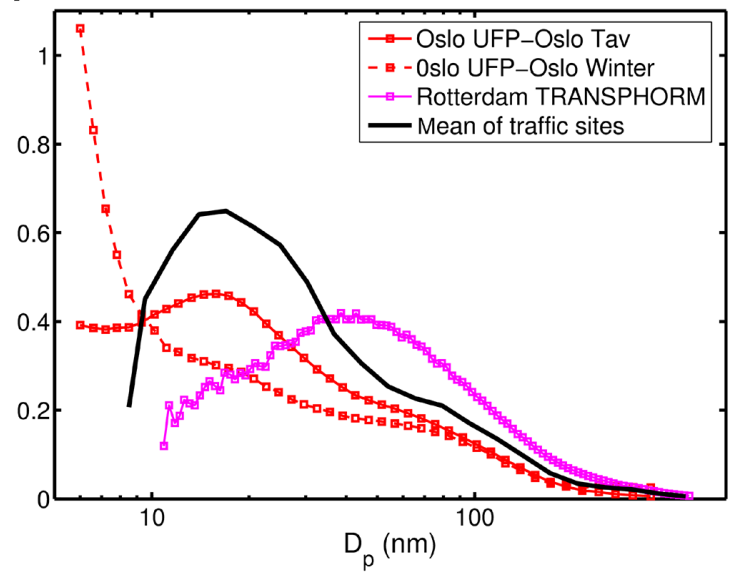

Figure 3. Measured size distribution data normalized to total PN concentration at different traffic stations: (a) Helsinki SAPPHIRE Case I, Helsinki SAPPHIRE Case II, Helsinki LIPIKA, Helsinki MMEA, and (b) Oslo Smestad Tav case, Oslo Smestad Winter case, Rotterdam Bentinckplein. Urban background concentrations have not been subtracted. The "mean of traffic sites" curve (solid black line) was constructed based on the mean of the size distribution curves for all traffic sites (Bentinckplein, Smestad, Itäväylä, Mannerheimintie) in all campaigns, after synchronization of the size bin diameters. The "mean of traffic sites" curve is displayed in both panels (a, b).

$25 \mathrm{~km} \mathrm{~h}^{-1}$ with stop-and-go driving, whereas at Itäväylä vehicles could drive $60-80 \mathrm{~km} \mathrm{~h}^{-1}$ very fluently.

The peak of the size distribution for UFP-Oslo Winter was below $10 \mathrm{~nm}$ and for Helsinki SAPPHIRE Case II the peak was below $20 \mathrm{~nm}$. Both campaigns were during winter in Northern Europe; ambient temperature in UFP-Oslo Winter ranged from -12 to $-8{ }^{\circ} \mathrm{C}$ and SAPPHIRE Case II ranged from -15 to $-4{ }^{\circ} \mathrm{C}$. The relative increase of nanoparticle numbers in cold conditions may be the result of increased nucleation of semi-volatile compounds post-emission and decreased saturation ratio of the condensing vapors that tend to enhance initial particle growth. It has also been reported that particle emission from light-duty diesel vehicles are influenced by low ambient temperatures during the vehicle coldstart (Mathis et al., 2005). However, the primary effect of a cold environment on vehicle cold-start is a number increase of semi-volatile nucleation mode particles, not of the solid particles in the exhaust (Maricq, 2007).

Accumulation mode particles have a longer lifetime in the atmosphere, it is therefore likely that they are either a result of ageing processes on the urban timescale or that they are from short-range or long-range transport of aerosols. Since the size distribution measurements were carried out at traffic sites at distances of a few meters from busy roads, the measured aerosols are expected to be mainly influenced by primary traffic emissions. However, for the campaigns at Rotterdam and Oslo, measurements were not always downwind from the traffic emissions, and could be influenced also by other local particle sources and secondary pollution from local traffic.

The number size distribution at Rotterdam showed an exceptionally broad peak mode at $30-70 \mathrm{~nm}$ and a large frac- tion of ACC particles. Other sources, such as emissions from harbor activities and refineries situated in the harbor area, could have contributed to the relatively high fraction of ACC particles at Bentinckplein. Average wind direction during the Rotterdam campaign was from southwest, from the direction of the harbor area "Nieuw Mathenesse". At an average wind speed of $3.6 \mathrm{~m} \mathrm{~s}^{-1}$, the travel time of particles from the harbor and refineries to the traffic site was about $15 \mathrm{~min}$. Ships emit large amounts of particles larger than $20 \mathrm{~nm}$, which consist of soot and volatile material (e.g. Fridell et al. 2008; Petzold et al., 2008; Kasper et al., 2007). Number size distributions of ship emissions in the ports of Helsinki and Turku (Finland) measured by "Sniffer" showed peaks at around 2030 and 80-100 nm (Pirjola et al., 2014).

Truck traffic in the harbor during loading and unloading of ships also leads to increased particle numbers (Pirjola et al., 2014). Measurements downwind of a harbor at Rotterdam showed that $61 \%$ of the PN concentration was in the size range $25-100 \mathrm{~nm}$ while it was $48 \%$ downwind of a motorway (Keuken et al., 2012). Condensation of vapors onto particles emitted from ships during their transport to the traffic site might explain the relatively high number concentration of ACC particles in the Rotterdam campaign. We note that the measured PN concentration of ACC particles in Rotterdam was similar as in Oslo but lower than during the LIPIKA and MMEA campaigns in Helsinki.

\subsection{Comparison of the model predictions against the campaign measurements}

The evolution of the particle size distribution as function of time up to $1 \mathrm{~h}$ for all the cases, and by definition, follow- 
ing increasing distance from the roadside (idealized scenario, Sect. 2.2), was studied with the one-dimensional aerosol dynamics model MAFOR and compared to measured size distributions data from the respective campaigns. Figures 4 and S2 show the comparison of modeled number size distributions from the idealized scenarios and the measured number size distribution at the roadside and at the urban background site for campaigns at Oslo, Rotterdam, and Helsinki. As the air parcel containing vehicle exhaust leaves street scale it is assumed to be advected over a homogenous surface in the neighborhood with a length scale of a few kilometers and further to the city scale. In the model, initial particle concentrations in all size bins were diluted with background air containing particles with a size distribution that matched the measured size distribution at the urban background site. In this way, the modeled size distributions were forced by the applied dilution scheme to relax towards the background size distribution, with a time constant dictated by the respective dilution scheme parameters. An in-depth evaluation of the aerosol dynamics model has not been carried out in the frame of this study, as the main focus was on the model's responses to changes in the treatment of aerosol microphysics.

The modeled number size distribution calculated for moderate dispersion conditions after $\sim 10 \mathrm{~min}$ of travel time, corresponding to a distance of $3600 \mathrm{~m}$ from the roadside, was generally in good agreement with the size distribution measured at the urban background site. Note that modeled size distributions range from $1 \mathrm{~nm}$ (lower bound) to $10000 \mathrm{~nm}$ (upper bound); in Fig. 4 the relevant size range of $6-1000 \mathrm{~nm}$ is shown. Dilution was the dominant process changing the size distribution between roadside and urban background, as shown by the continuous decrease of concentrations with time. For the campaigns Helsinki SAPPHIRE Case I (Fig. 4c) and Case II (Fig. S2c), as well as Helsinki MMEA (Fig. 4d) the maximum of the particle size distribution was moved to a larger diameter. For instance, the modeled size distribution in Helsinki SAPPHIRE Case I showed an increase of the nucleation mode peak diameter from 10 to $18 \mathrm{~nm}$ within a distance of $3600 \mathrm{~m}$. This behavior can be explained by dilution transforming the shape of the roadside distribution into the (prescribed) shape of the urban background distribution. UFP-Oslo Winter (Fig. 4a) shows signs of growing small particles by condensation, with peak diameter moving from ca. 5 to $8 \mathrm{~nm}$.

Model simulations using different wind speed and dilution parameters, representative for different dispersion conditions (efficient, moderate, inefficient dispersion; as given in Table 1), were performed for each campaign. The contribution of the various aerosol dynamic processes to the change of total PN at a given travel time was derived by switching off the respective aerosol process in the model calculation. The percentage $\mathrm{PN}$ change due to a specific aerosol dynamic process was obtained by division of the total PN change with the total $\mathrm{PN}$ change when all processes were considered (PN change defined as difference between initial total particle number and total particle number after a certain travel time). Table 4 summarizes the PN change after $30 \mathrm{~min}$ of travel time due to each selected aerosol process, and also to dilution, in each of the campaigns for efficient, moderate and inefficient dispersion conditions. The considered aerosol processes accounted for PN concentration changes of up to $20 \%$ after $10 \mathrm{~min}$ and up to $\sim 30 \%$ after $30 \mathrm{~min}$ (Fig. 5), respectively.

According to the results shown in Table 4, coagulation and dry deposition were relevant aerosol dynamic processes for particle removal in the Rotterdam campaign whereas dry deposition was the predominant aerosol process in the Oslo campaign. Due to identical dispersion conditions and wind speeds used in the comparison, the observed difference is attributed to the different shapes of the initial size distribution measured at the roadside station and the background particle size distributions. The larger fraction of particles with diameter $>25 \mathrm{~nm}$ measured at Rotterdam (accounting for $73 \%$ of total PN) explains the higher relevance of coagulation compared to the Oslo campaign. Particles with larger diameter more efficiently scavenge the small $(<25 \mathrm{~nm}$ diameter) particles by coagulation.

For the LIPIKA and MMEA campaigns coagulation was the most important aerosol process for particle removal during low wind speed. The size distributions for LIPIKA and MMEA (green and cyan lines in Fig. 3a) peak in a size range between 10 and $40 \mathrm{~nm}$ diameter and show a higher fraction of ACC particles than the SAPPHIRE distributions. Obviously, coagulation becomes a relevant PN loss process once large numbers of particles below $50 \mathrm{~nm}$ diameter from vehicle exhaust emissions (e.g. ca. 92000 particles $\mathrm{cm}^{-3}$ at roadside, LIPIKA) are accompanied by a significant PN fraction of larger particles, which originate either from other local sources or from secondary particle formation within the urban area. These results are in agreement with the ones by Kerminen et al. (2007) who estimated that the lower and upper limits for the inter-modal coagulation timescale during the rush hours were 15-20 and 60-80 min, respectively. During the night, the inter-modal coagulation timescale was 23 times that during the rush hours (Kerminen et al., 2007).

The contribution of dry deposition and coagulation to total PN losses is comparable to those determined in previous measurements and model studies. City scale modelling studies with a multi-plume aerosol dynamics and transport model indicated that coagulation and dry deposition can cause total PN losses of 15-30\% between roadside measurement and urban background measurement in Copenhagen (Ketzel and Berkowicz, 2005). Gidhagen et al. (2005), using an urban dispersion model that included aerosol dynamics in Stockholm, concluded that in terms of time-averaged PN concentration, dry deposition may yield particle number losses of up to $25 \%$ in certain locations, while coagulation contributed little to PN losses. During particle peak episodes the removal by dry deposition and coagulation was more substantial (Gidhagen et al., 2005). 

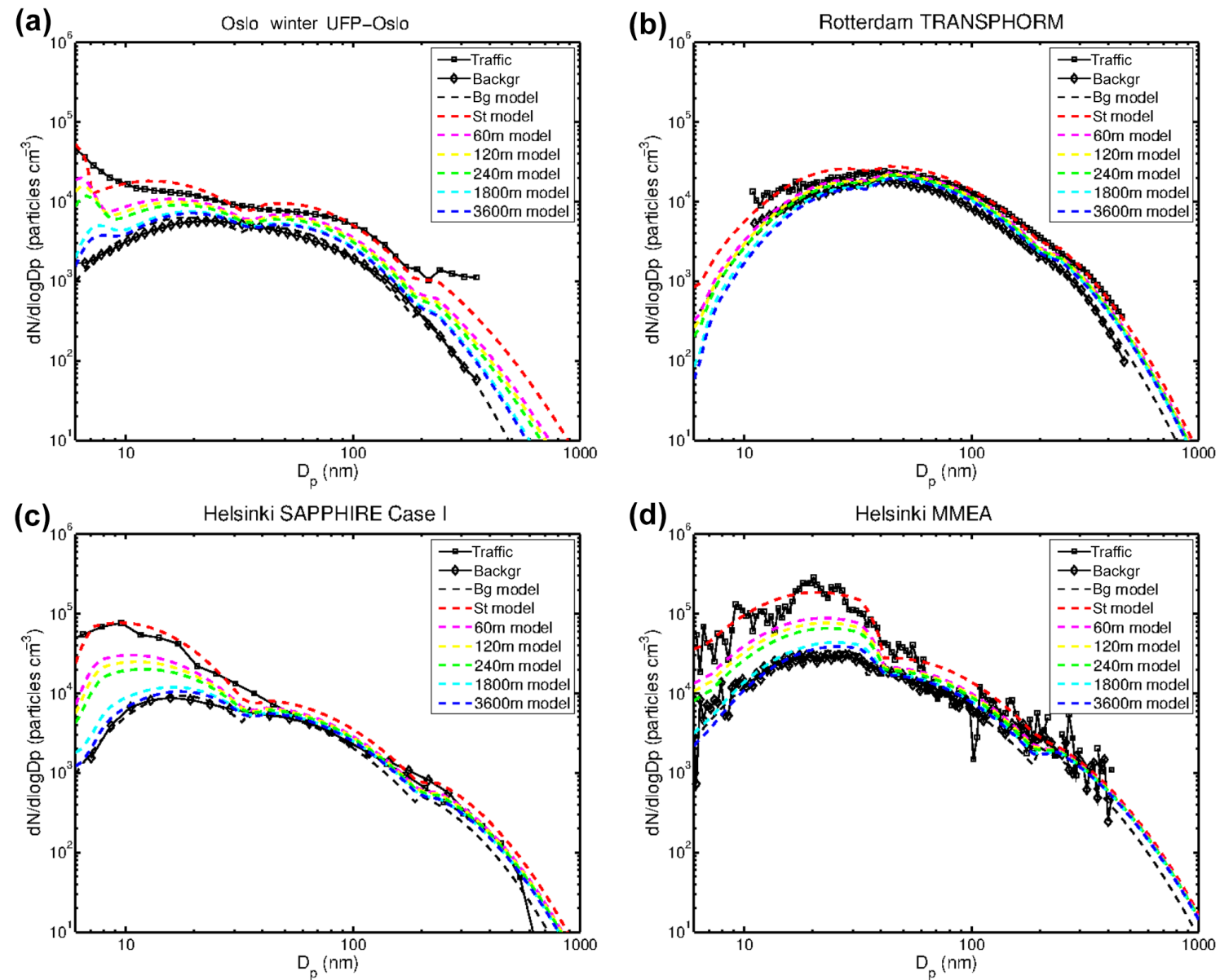

Figure 4. Size distributions $\left(\mathrm{d} N / \mathrm{d} \log D_{\mathrm{p}}\right.$ in particles $\left.\mathrm{cm}^{-3}\right)$ downwind of roads in selected campaigns: (a) Oslo, UFP-Oslo Winter, (b) Rotterdam, (c) Helsinki SAPPHIRE Case I, and (d) Helsinki MMEA. The plots show the measured distribution at roadside (black squares connected by line), the measured distribution at urban background (black diamonds connected by line), the initial model distribution (roadside: dashed red line, background: dashed black line) and the modeled distributions (resulting for moderate dispersion conditions) at distances of $60,120,240,1800$, and $3600 \mathrm{~m}$, respectively. Size distributions are shown with a lower size cut-off at $6 \mathrm{~nm}$.

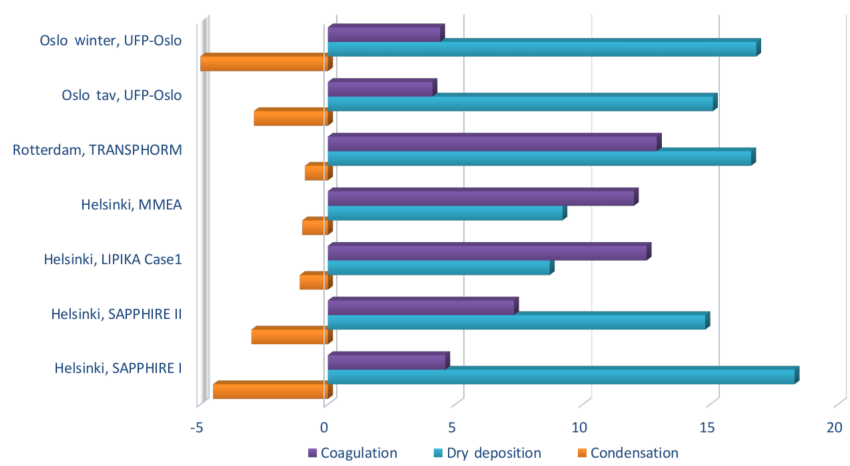

Figure 5. Contribution of aerosol processes to the percentage change of PN concentration (\%) between roadside station and neighborhood environment for inefficient dispersion conditions after 30 min transport time in all campaigns.
Condensation and evaporation of vapors as such is not expected to change the total number concentrations, however this can modify the particle size distributions and particle volume. In this study a significant increase of PN (by up to $8 \%$ after 30 min travel time) was evident under inefficient dispersion conditions, when condensation was considered in addition to coagulation and dry deposition. The reason could be the competition between condensation and coagulation. As the air parcel moves away from the roadside, condensation of condensable organic vapors leads to rapid growth of small particles to larger diameters at which they are less affected by coagulational loss. In addition, dry deposition velocity decreases with increasing diameter between 1 and $100 \mathrm{~nm}$. Hence particles grown by condensation of condensable organic vapors will be less affected by deposition.

Aerosol dynamics are less relevant under conditions with efficient dispersion. When efficient dispersion occurs in the urban canopy, dilution by background air is the only effec- 
Table 4. Contribution of processes coagulation (Coag), dry deposition (Dry dep), condensation (Cond) and dilution (Dil) to change of PN concentration $(\%)$ between roadside station and neighborhood environment after $30 \mathrm{~min}$ transport time for different dispersion conditions (i.e., $(\Delta \mathrm{PN}$ process $/(\mathrm{PN}($ initial $)-\mathrm{PN}($ end $))) \times 100 \%$; with $\Delta \mathrm{PN}_{\text {process }}$ being the change due to the respective process after 30 min $)$. Values in bold denote the range (minimum to maximum) of PN changes (\%) for all campaigns and dispersion conditions.

\begin{tabular}{|c|c|c|c|c|c|c|c|c|c|c|c|c|}
\hline \multirow[t]{2}{*}{ City and campaign } & \multicolumn{4}{|c|}{ Efficient dispersion } & \multicolumn{4}{|c|}{ Moderate dispersion } & \multicolumn{4}{|c|}{ Inefficient dispersion } \\
\hline & Coag & Dry dep & Cond & Dil & Coag & Dry dep & Cond & Dil & Coag & Dry dep & Cond & Dil \\
\hline Rotterdam TRANSPHORM & 4.7 & 0.9 & 0.0 & 94.4 & 7.5 & 4.3 & -0.1 & 88.4 & 12.9 & 16.6 & -0.9 & 71.4 \\
\hline Oslo UFP-Oslo Tav & 0.5 & 0.4 & 0.0 & 99.1 & 0.8 & 2.6 & -0.1 & 96.8 & 4.1 & 15.1 & -2.9 & 83.7 \\
\hline Oslo UFP-Oslo Winter & 0.5 & 0.4 & 0.0 & 99.1 & 0.8 & 2.8 & -0.1 & 96.5 & 4.4 & 16.8 & -5.9 & 84.7 \\
\hline Helsinki SAPPHIRE Case I & 0.4 & 0.3 & 0.0 & 99.3 & 0.7 & 3.2 & 0.0 & 96.1 & 4.6 & 18.3 & -4.5 & 81.6 \\
\hline Helsinki SAPPHIRE Case II & 0.7 & 0.4 & 0.0 & 98.8 & 1.2 & 2.4 & 0.0 & 96.3 & 7.3 & 14.8 & -3.0 & 80.9 \\
\hline Helsinki LIPIKA & 1.1 & 0.2 & 0.0 & 98.7 & 2.2 & 1.0 & -0.1 & 95.9 & 12.5 & 8.7 & -1.1 & 79.9 \\
\hline Helsinki MMEA & 1.3 & 0.3 & 0.0 & 98.5 & 2.2 & 1.6 & -0.1 & 96.2 & 12.0 & 9.2 & -1.0 & 79.8 \\
\hline \multicolumn{13}{|l|}{ All campaigns } \\
\hline \multirow[t]{2}{*}{ City and campaign } & \multicolumn{4}{|c|}{$\begin{array}{l}\text { All dispersion conditions } \\
\text { Range (min-max) }\end{array}$} & & & & & & & & \\
\hline & Coag & Dry dep & Cond & Dil & & & & & & & & \\
\hline Rotterdam TRANSPHORM & $4.7-12.9$ & $0.9-16.6$ & $-0.9-0.0$ & $71.4-94.4$ & & & & & & & & \\
\hline Oslo UFP-Oslo Tav & $0.5-4.1$ & $0.4-15.1$ & $-2.9-0.0$ & $83.7-99.1$ & & & & & & & & \\
\hline Oslo UFP-Oslo Winter & $0.5-4.4$ & $0.4-16.8$ & $-5.9-0.0$ & $84.7-99.1$ & & & & & & & & \\
\hline Helsinki SAPPHIRE Case I & $0.4-4.6$ & $0.3-18.3$ & $-4.5-0.0$ & $81.6-99.3$ & & & & & & & & \\
\hline Helsinki SAPPHIRE Case II & $0.7-7.3$ & $0.4-14.8$ & $-3.0-0.0$ & $80.9-98.9$ & & & & & & & & \\
\hline Helsinki LIPIKA & $1.1-12.5$ & $0.2-8.7$ & $-1.1-0.0$ & 79.9-98.7 & & & & & & & & \\
\hline Helsinki MMEA & $1.3-12.0$ & $0.3-9.2$ & $-1.0-0.0$ & $79.8-98.5$ & & & & & & & & \\
\hline $\begin{array}{l}\text { All campaigns } \\
\text { Range (min-max) }\end{array}$ & $0.4-12.9$ & $0.2-18.3$ & $-5.9-0.0$ & $71.4-99.3$ & & & & & & & & \\
\hline
\end{tabular}

tive process reducing PN concentration with distance from the roadside. In such situations (dilution parameters: $a=$ $80, b=0.9$ ) aerosol processes account for PN concentration changes of less than $3 \%$ after $10 \mathrm{~min}$ and PN concentration changes of less than $6 \%$ after $30 \mathrm{~min}$, hence modelling of $\mathrm{PN}$ as passive tracer is adequate. According to the previously published model study at the Dutch motorway A16; the particle size distribution at $D_{\mathrm{p}}>40 \mathrm{~nm}$ is not further altered by aerosol processes after a distance of $1000 \mathrm{~m}$ from the roadside (Keuken et al., 2012). The distance where the PN level reaches background concentrations depends on dispersion conditions. Background PN levels were reached approximately (within an accuracy of $\pm 5 \%$ ) after 1740, 900, and $160 \mathrm{~m}$ in distance from the road for inefficient, moderate, and efficient dispersion conditions, respectively, in box model simulations using the Rotterdam campaign data.

\subsection{Effect of dry deposition of particles to different surface types}

The sensitivity of modeled PN concentrations towards dry deposition of particles on various surface types and roughness conditions were studied in the campaigns Rotterdam TRANSPHORM and UFP-Oslo Tav under moderate dispersion conditions. Two different deposition methodologies, KS2012 and H2012 (detailed description in Sect. 2.3), were applied. Results from the sensitivity tests are summarized in Table S2.
Between different KS2012 cases, calculated dry deposition velocity, $v_{\mathrm{d}}$, spanned about 1 order of magnitude for all particle diameters. Case "KS2012 Urban" corresponded to the surface characteristics of typical urban environments, i.e. streets and buildings, as used for the reference model runs with MAFOR. KS2012 parameterization was not sensitive to changes of friction velocity or roughness length within a typical urban range of values: reducing friction velocity (case "Low friction") or increasing roughness length (case "High roughness") resulted in negligible $(\leq 0.1 \%)$ change of PN loss due to dry deposition compared to case "Urban". Over grassland and forest, modeled PN concentration changes due to dry deposition were smaller by 30 and $50 \%$, respectively, than over urban surfaces.

Using the deposition methodology H2012 for case "Urban" resulted in 40-50\% lower PN losses by dry deposition compared to KS2012. Between different H2012 cases calculated $v_{\mathrm{d}}$ spans about 2 orders of magnitude for accumulation mode particles $\left(D_{\mathrm{p}} 100-1000 \mathrm{~nm}\right)$ which can be attributed to the fact that surface roughness becomes a dominant factor in collecting aerosol particles efficiently for that particle size range, where neither diffusion nor inertial processes are significant processes. H2012 parameterization was very sensitive to changes of friction velocity or roughness length. The contribution of dry deposition to PN changes varied by roughly a factor of 5 for Rotterdam and by a factor of 3-4 for Oslo due to changing roughness conditions.

It has been evident in the literature (e.g., Guha, 1997), that surface roughness can increase $v_{\mathrm{d}}$ by up to 2 orders of mag- 
nitudes, in the size range between particle diffusion regime and diffusion-impaction regime, compared to a smooth surface. This behavior is reflected by the $\mathrm{H} 2012$ parameterization, but not by the KS2012 parameterization.

\subsection{Effect of condensation and evaporation of organic compounds}

Inspection of the modeled evolution of number size distributions in simulations of Helsinki LIPIKA (moderate dispersion) revealed that variation of organic vapor concentration mainly affected the nucleation mode. Compared to a simulation without condensation and evaporation, the reference case with $0.5 \mathrm{ppb}$ condensable organic vapors (sum of C22 and $\mathrm{C} 28$ gas-phase concentration with ratio 50:50) did not significantly change the number size distribution in a distance of $240 \mathrm{~m}$ from the road (Fig. S3a) but doubled the mass of $10 \mathrm{~nm}$ particles (Fig. S3b). When the concentration of condensable organic vapors was reduced to $0.05 \mathrm{ppb}$ or below, condensation became completely negligible. Our sensitivity results are qualitatively in line with the study of Pohjola et al. (2007) who, based on measured PN data and the aerosol dynamics model MONO32 (Pirjola et al., 2003), found that the influence of condensation on PN concentrations was negligible on a distance scale of $200 \mathrm{~m}$ near a major road in Helsinki. For example, presence of a condensable organic compound with $\sim 0.4 \mathrm{ppb}$ increased the diameter in the two smallest particle size modes by only 14 and $1.9 \%$, respectively (Pohjola et al., 2007).

An extreme case to test the relevance of condensing nalkane vapor and its effect on traffic-related size distributions was the Oslo Winter data (Fig. 4a). Under inefficient dispersion conditions, modeled total PN concentration in UFPOslo Winter was $2 \%$ higher after a distance of $240 \mathrm{~m}$ with $0.5 \mathrm{ppb}$ condensable organic vapors, compared to a simulation without condensation. Growth of particles by condensation caused a shift of the nucleation mode diameter from 5.9 to $8.8 \mathrm{~nm}$ (Fig S4a), thus increasing the survival probability of the very small particles. Two factors enhanced the effect of condensation on the changing size distribution: first, the low temperature causing low vapor pressure (a factor of 90 smaller than at $10^{\circ} \mathrm{C}$ ) and second, the high fraction of initially present particle numbers with diameter below $10 \mathrm{~nm}$. For lower concentrations of condensable organic vapors, 0.05 and $0.005 \mathrm{ppb}$, no significant particle growth was found (mass size distribution in Fig. S4b). Evaporation of particles $<10 \mathrm{~nm}$ diameter occurred at $0.005 \mathrm{ppb}$, when changing the organic fraction of nucleation mode particles to $100 \% \mathrm{C} 22$, i.e., assuming higher volatility of vehicular nanoparticles that formed post-emission. Interestingly, the evaporated material partly re-condensed to particles with diameter $>100 \mathrm{~nm}$ within $240 \mathrm{~m}$ distance from the roadside (blue dashed line in Fig. S4a, b).

The growth of small particles $\left(D_{\mathrm{p}}<10 \mathrm{~nm}\right)$ at $0.5 \mathrm{ppb}$ condensable organic vapors to larger sizes within a distance of $240 \mathrm{~m}$ in campaign UFP-Oslo Winter corroborates the finding in a curbside study by Zhang et al. (2004) at two freeways in Los Angeles, that a large number of emitted sub$6 \mathrm{~nm}$ particles can grow substantially 30-90 m downwind. However, it cannot be excluded that downwind emissions of vehicle pollutants or oxidized volatile organic compounds (VOC) contributed to the observed growth.

Model simulations of the idealized scenario suggest that evaporation could be an important process, altering the particle size distribution in urban micro-environments, if the semi-volatile vapor and also the nanoparticles forming postemission were assumed to have the same or higher volatility as the n-alkane C22. Dall'Osto et al. (2011) analyzed observations of particle size distributions from London and reported a reduction in the size of nucleation mode particles during advection from a major highway into the cleaner environment of a park, indicating evaporative loss of semivolatile constituents during travel times of around $5 \mathrm{~min}$. Harrison et al. (2016), for the same location, found most rapid evaporation to occur at higher wind speeds, associated with shorter travel times, but cleaner air.

\subsection{Effect of fractal geometry of soot particles and van der Waals forces}

Model calculations for the idealized scenario assumed that all particles are spherical. However, soot particles emitted from diesel vehicles are fractal-like aggregates consisting of nanosized primary spherules. The effect of fractal geometry on coagulation was taken into account by considering the effect on radius, diffusion coefficient and the Knudsen number in the Brownian collision kernel. In order to test how fractal geometry of soot particles affects the modeled particle size distribution and PN concentrations, the coagulation kernel in MAFOR was modified by assuming that the collision radius is equal to the fractal (outer) radius, $r_{\mathrm{f}}$, defined as (Jacobson and Seinfeld, 2004)

$r_{\mathrm{f}, i}=r_{\mathrm{s}} \times n_{\mathrm{s}, i}^{1 / D_{\mathrm{f}}}$,

where $n_{\mathrm{S}}=v_{i} / v_{\mathrm{S}}$ is the number of primary spherules in the soot aggregate, $v_{i}$ is the volume of the aggregate, treated as if it were spherical, $r_{\mathrm{s}}$ is the radius of spherules and $v_{\mathrm{s}}$ is the volume of a spherule that makes up the aggregate, and $D_{\mathrm{f}}$ is the fractal dimension. Soot particle density was corrected as explained in Lemmetty et al. (2008).

Van der Waals forces and viscous interactions affect the coagulation rate of small particles. It has been shown that van der Waals forces can enhance the coagulation rate of particles with diameter $<50 \mathrm{~nm}$ by up to a factor of five (Jacobson and Seinfeld, 2004). To evaluate how neglecting the two forces affected the particle size distribution evolution, a correction factor $V_{\mathrm{E}, i, j}$ accounting for van der Waals and viscous forces was applied to the Brownian collision kernel, $K_{i, j}^{\mathrm{B}}$, for the collision of particle of size bin $i$ with particles of size bin $j$ 
in the MAFOR model:

$K_{i, j}^{\mathrm{corr}}=K_{i, j}^{\mathrm{B}} \times V_{\mathrm{E}, i, j}$.

Refer to Sect. S3 for details of the implementation. The effect of van der Waals forces and viscous interactions as well as fractal geometry on the Brownian collision kernel is shown in Fig. S5. Parameters of the fractal geometry adapted from Jacobson and Seinfeld (2004), $r_{\mathrm{s}}=13.5 \mathrm{~nm}$ and $D_{\mathrm{f}}=1.7$, resulted in stronger enhancement of the coagulation rate for collisions with a $10 \mathrm{~nm}$ particle than the parameters $\left(r_{\mathrm{s}}=2.5 \mathrm{~nm}\right.$ and $\left.D_{\mathrm{f}}=2.5\right)$ adapted from Lemmetty et al. (2008).

The combination of both effects substantially enhanced the loss of nanoparticles in the simulation of the evolution of the roadside aerosol. For Helsinki MMEA, inefficient dispersion conditions, the enhancement was similar for the two effects separately, i.e., spherical particles with van der Waals and viscous forces versus fractal particles (Fig. S6). The combined effect increased the loss of total PN by $15 \%$ compared to the reference simulation (coagulation of spherical particles by Brownian motion) in $600 \mathrm{~m}$ distance from the road.

\subsection{Uncertainties of the aerosol treatment in the idealized scenario}

Computation of the aerosol evolution between the roadside station and the neighborhood environment with the idealized scenarios involves several assumptions and uncertain parameters. An uncertainty analysis was performed to quantify the errors associated with the determination of the contribution of the respective atmospheric processes to the change of total PN. Errors were determined based on simulations for the mean traffic-related particle distribution (Sect. 3.1) under inefficient dispersion conditions after $30 \mathrm{~min}$ travel time (Fig. 6).

Fractal parameters of Jacobson and Seinfeld (2004) were chosen for the evaluation of the uncertainty of the coagulation process. The combined effect of fractal geometry and van der Waals plus viscous interactions was taken into account, resulting in an error of $+130 \%$, roughly corresponding to a doubling of the contribution of coagulation to PN losses between roadside station and the neighborhood.

Measurements of dry deposition velocities of particles for one particular surface type generally vary by 1 order of magnitude for a given particle size range of a half logarithmic decade (e.g., for different grassland and forest types; Petroff et al., 2008). Dry deposition velocities for total PN (0.2$\left.0.9 \mathrm{~cm} \mathrm{~s}^{-1}\right)$, calculated with the reference case parameterization "KS2012 Urban", correspond to the reported range of measured deposition velocity values. Here, dry deposition velocity was scaled by factor 2 and $1 / 5$ to evaluate the uncertainty of the dry deposition process due to literature span of measured velocities. This resulted in an error margin from -76 to $+64 \%$ for the contribution from dry deposition.
For the mean traffic-related particle distribution, evaporation contributed $0.3 \%$ to $\mathrm{PN}$ losses when assuming $0.005 \mathrm{ppb}$ $\mathrm{C} 22+\mathrm{C} 28$ and $100 \% \mathrm{C} 22$ in $<10 \mathrm{~nm}$ particles. Condensation and evaporation are uncertain processes due to the lack of measurements of the gas-phase and particle phase concentrations of condensable compounds at the roadside station. Oxidation of VOC from vehicular emissions may provide an additional source of condensable material on the neighborhood scale. However, oxidized VOC in the background air are expected to condense on the particles of the accumulation mode, increasing their volume, rather than changing PN concentrations.

Additional emissions of particles on the travel path between the roadside station and the background were not considered in the idealized scenario. Since the dilution process in the model simulations was constrained with the measured size distribution at the background, the influence of additional particle emissions has been implicitly taken into account. However, if there are strong emission sources of ultrafine particles on the way, the momentary particle size distribution might be perturbed. The error due to fluctuations of the dilution rate caused by additional emissions was estimated to be $-4 \%$.

The main uncertain parameter in the applied dilution scheme (Eqs. 1, 2) is the initial plume height at the roadside, $H_{m, 0}$. Doubling $H_{m, 0}$ resulted in a small error $(-1 \%)$ of the contribution of dilution to PN losses.

It is concluded that errors due to the design of the scenario (dilution scheme, additional emissions) are relatively small compared to the magnitude of the potential contribution of coagulation and dry deposition to total PN losses between roadside station and the neighborhood environment.

\subsection{The recommended simplified parametrizations of aerosol processes}

As a first step of the implementation of a treatment of aerosol processes in urban air quality models, a separation of PN to various size categories is required. Three particle number concentration (PNC) categories were defined, as follows: $\mathrm{PNC}_{1}\left(8.5 \mathrm{~nm}<D_{\mathrm{p}}<25 \mathrm{~nm}\right.$; "Nucleation mode"), $\mathrm{PNC}_{2}\left(25 \mathrm{~nm}<D_{\mathrm{p}}<100 \mathrm{~nm}\right.$; "Aitken mode"), and $\mathrm{PNC}_{3}$ $\left(100 \mathrm{~nm}<D_{\mathrm{p}}<500 \mathrm{~nm} ; \mathrm{ACC}\right)$. The upper boundary of $500 \mathrm{~nm}$ is justified because the contribution of large particles (defined here as $>500 \mathrm{~nm}$ ) to total PN concentration from vehicular exhaust is negligible.

A first-order rate law for PNC in the three size categories (index $k$ ) was derived for number concentration change with time due to dry deposition:

$\ln \left(\frac{\mathrm{PNC}_{k}}{\mathrm{PNC}_{k, 0}}\right)=-\frac{\overline{v_{\mathrm{d}, k}}}{H_{m}} \times t$,

where $\mathrm{PNC}_{k, 0}$ is initial concentration. The average dry deposition velocity $\overline{\nu_{\mathrm{d}, k}}$ was determined by fitting a linear regression model to the time series of modeled $\mathrm{PNC}_{1}, \mathrm{PNC}_{2}$, and 
Table 5. Data required for the implementation of the PNC parameterization for dry deposition according to three different methodologies and for coagulation. Typical urban times scales for dry deposition $\left(\tau_{\mathrm{depo}}\right)$ and for coagulation $\left(\tau_{\mathrm{coag}}\right)$ is given as reference. MAFOR uses a large number of bin sizes so the extracted coefficients for the three size categories are based on an integral and/or average over a number of bins in the model. The initial size distribution ratio is the PN fraction in each PNC category for the "mean of traffic sites" distribution. Dry deposition velocity and timescale was calculated with three different methods: KS2012 (Kouznetsov and Sofiev, 2012), H2012 (Hussein et al., 2012), and S1985 (Schack Jr. et al., 1985).

\begin{tabular}{|c|c|c|c|c|c|c|c|c|c|c|}
\hline $\begin{array}{l}\text { Size } \\
\text { category }\end{array}$ & $\begin{array}{r}\text { Size } \\
\text { ranges } \\
(\mathrm{nm})\end{array}$ & $\begin{array}{r}\text { Initial } \\
\text { size distr. } \\
\text { ratio }(-)\end{array}$ & $\begin{array}{r}v_{\mathrm{d}} \\
\mathrm{KS} 2012 \\
\left(\mathrm{cms}^{-1}\right)\end{array}$ & $\begin{array}{r}v_{\mathrm{d}} \\
\mathrm{H} 2012 \\
\left(\mathrm{cms}^{-1}\right)\end{array}$ & $\begin{array}{r}v_{\mathrm{d}} \\
\mathrm{S} 1985 \\
\left(\mathrm{cms}^{-1}\right)\end{array}$ & $\begin{array}{r}K_{\text {coag }} \\
\left(\mathrm{cm}^{3} \mathrm{~s}^{-1}\right)\end{array}$ & $\begin{array}{r}\tau_{\text {depo }} \\
\mathrm{KS} 2012 \\
(\mathrm{~h})\end{array}$ & $\begin{array}{r}\tau_{\text {depo }} \\
\mathrm{H} 2012 \\
(\mathrm{~h})\end{array}$ & $\begin{array}{r}\tau_{\text {depo }} \\
\text { S1985 } \\
(\mathrm{h})\end{array}$ & $\begin{array}{r}\tau_{\text {coag }} \\
\text { (h) }\end{array}$ \\
\hline $\mathrm{PNC}_{1}$ & $8.5-25$ & 0.70 & 0.53 & 0.20 & 0.87 & $4.51 \times 10^{-9}$ & 1.1 & 2.8 & 0.6 & 1.9 \\
\hline $\mathrm{PNC}_{2}$ & $25-100$ & 0.29 & 0.12 & 0.08 & 0.19 & $3.10 \times 10^{-9}$ & 4.7 & 6.7 & 2.9 & 6.6 \\
\hline $\mathrm{PNC}_{3}$ & $100-500$ & 0.01 & 0.02 & 0.07 & 0.03 & $8.82 \times 10^{-10}$ & 24 & 8.5 & 17 & 589 \\
\hline
\end{tabular}

$\mathrm{PNC}_{3}$, from a MAFOR run initialized with the size distribution "mean of traffic sites" (see Sect. 3.1) and dry deposition as only process.

In Eulerian models, dry deposition of particles can be implemented according to

$\left.\frac{\mathrm{dPNC}_{k}}{\mathrm{~d} t}\right|_{\text {depo }}=-\mathrm{PNC}_{k} \frac{\overline{\nu_{\mathrm{d}, k}}}{H_{\text {grid }}}$.

Here $H_{\text {grid }}$ is the depth of the lowest grid level. Table 5 provides average dry deposition velocity derived from the fit to Eq. (5). If applying the parameterization in a Gaussian model then the deposition velocity is usually used to influence the reflection parameter $(\alpha)$ for the reflected plume, e.g., using the following equation (Hanna et al., 1982):

$\alpha_{k}(x)=1-\frac{2 \overline{\mathrm{d}_{\mathrm{d}, k}}}{v_{t}+\overline{v_{\mathrm{d}, k}}+\left(U h-v_{t} x\right) \times \sigma_{z}^{-1}\left(\frac{\mathrm{d} \sigma_{z}}{\mathrm{~d} x}\right)}$,

where $h$ is the effective plume rise and $\sigma_{z}$ is the vertical dispersion coefficient. Gravitational settling velocity $v_{t}$ in Eq. (7) can be neglected (set to zero) since only particle sizes below $500 \mathrm{~nm}$ are relevant for determining PN concentrations.

Coagulation of particles can be implemented, rate according to

$\left.\frac{\mathrm{dPNC}_{k}}{\mathrm{~d} t}\right|_{\mathrm{coag}}=-\mathrm{PNC}_{k} \times\left(\overline{K_{\text {coag }, k}} \times \mathrm{PNC}_{k}^{0}\right)$,

where $\overline{K_{\text {coag, }, k}}$ (in units $\mathrm{cm}^{3} \mathrm{~s}^{-1}$ ) is the average coagulation coefficient in a size category $k$ derived from MAFOR calculations, provided in Table 5. The expression in Eq. (8) neglects the production terms of coagulation. The superscript 0 indicates the number concentration at the start of the time step calculation in Eulerian models. For Gaussian models this is the calculated concentration before the inclusion of the decay rate due to any physical and chemical processes considered for PNC.

Dry deposition and coagulation terms are applied separately for the three PNC classes. This means that coagulation

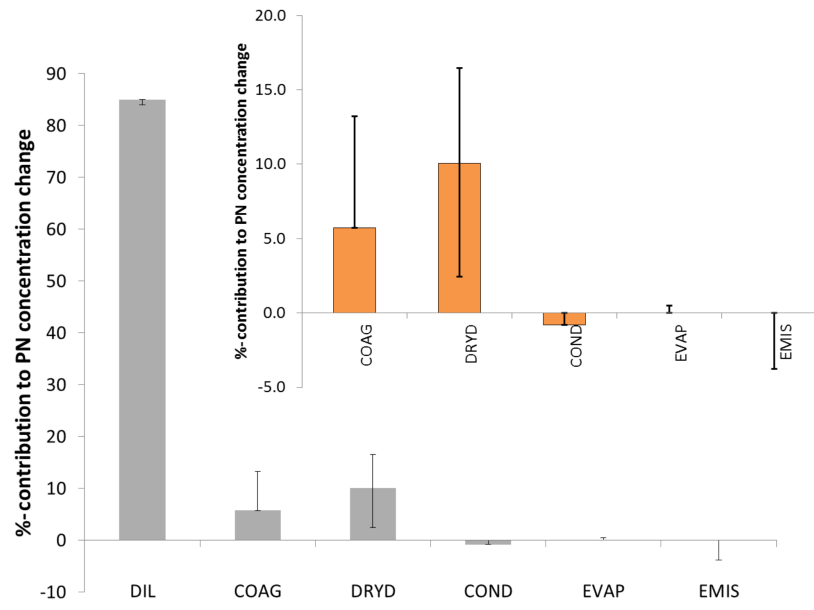

Figure 6. Contribution of processes to the percentage change of PN concentrations between roadside station and neighborhood environment, and their associated uncertainty depicted as error bars. Inset magnifies the contribution and uncertainty of the aerosol processes and additional emissions of particles.

between different size categories is not calculated explicitly with the parameterization. However, inter-modal coagulation is partly taken into account through the average coagulation coefficient derived from a model calculation that included coagulation between all size bins. Since the average coagulation coefficient of a given size category depends on the number concentrations in the other size categories, the predicted coagulational loss for $\mathrm{PNC}_{1}$ and $\mathrm{PNC}_{2}$ of roadside size distributions that differ from the size distribution "mean of traffic sites" will be somewhat inaccurate.

The accuracy of the presented parameterization for aerosol processes for prediction of $\mathrm{PN}$ concentrations is limited by three factors: first, by the averaging of process parameters over a certain size range; second by the simplified treatment of coagulation; and third by neglecting condensation and evaporation. The uncertainty of the parameterization was studied by comparison with PN concentrations resulting from a detailed aerosol dynamics calculation with MAFOR 
as reference. For the case "mean of traffic sites", calculated total PNC after 10 min travel time deviated from the reference solution by only $1 \%$, implying that the error introduced by size-averaged process parameters is negligible. When applying the parameterization to campaign data, the deviation of the total PNC to the reference solution was up to $10 \%$. UFP-Oslo Winter was excluded from the evaluation due to the obvious influence of condensation as shown in Sect. 3.4. Increasing the number of PNC size categories is expected to reduce the error due to neglecting coagulation between size categories. A parameterization with six PNC categories resulted in a deviation to the reference solution by only up to $5 \%$ (Table S3). In addition, the parameterization is uncertain due to assumptions about particle shape, neglecting van der Waals forces as well as inaccurate measured dry deposition velocities. It is however not affected by the specific treatment of dilution in the idealized scenarios because the simplified PNC parameterization was derived with only one aerosol process activated.

Results of PN concentration modelling for Oslo using the simplified parameterization for dry deposition and coagulation in the Eulerian urban dispersion model EPISODE (Slørdal et al., 2003) are presented in Kukkonen et al. (2016).

\section{Conclusions}

We have investigated the significance of aerosol processes during the atmospheric transport of particles on a timescale of 1 hour, i.e., from the roadside to the neighborhood scale, based on measurement campaigns and modelling in three European major cities. Most of the previous studies have been based on the results of one specific measurement campaign. Our analysis included size distribution data from several campaigns that were performed in different urban settings (street canyon, highway, and suburban main road), exhibiting different traffic characteristics and dispersion conditions, at different times of the year. Monitoring was done with stationary or mobile platforms, and size distributions were measured with various aerosol instruments. An advantage of this study is therefore that the results and conclusions about the relevance of aerosol processes do not depend critically on the specific conditions in terms of emissions, meteorology, and dispersion of a single campaign.

We have used the one-dimensional multicomponent aerosol dynamics model MAFOR to predict PN concentrations and number size distributions. We used a simplified treatment of the dilution of an air parcel from roadside to urban background to relax the model towards observed background size distributions. Three dispersion cases that are common for northern and central Europe were simulated, ranging from stagnant conditions to efficient dispersion. Despite the simple representation of atmospheric dispersion, size distributions predicted by the aerosol model after approximately $10 \mathrm{~min}$ of travel time $\left(U=3 \mathrm{~m} \mathrm{~s}^{-1}\right)$ compared well with the size distributions measured at the respective urban background sites.

A limitation of this study was that the chemical transformation of gas phase compounds was not taken into account. It was not necessary to evaluate the nucleation of gasphase vapors to form new particles, as the model simulations of this study were started at roadside conditions (instead of the exit of the tailpipes of vehicles). It was investigated how condensational growth might influence the shape of the particle size distribution between roadside and the neighborhood scale. Condensational growth did not substantially affect the temporal evolution of the PN concentrations in the presence of efficient and moderate dispersion conditions. The present study shows that growth by condensation can increase the survival probability of very small particles. Condensation removes the smallest particles $\left(D_{\mathrm{p}}<15 \mathrm{~nm}\right.$; Ketzel and Berkowicz, 2004) from the size distribution by growing them to larger sizes, which are less affected by removal through dry deposition and coagulation. An increase of the PN concentration was found between roadside and the neighborhood scale due to condensational growth under inefficient dispersion conditions. This result differs from that in some previous studies, which stated that the total number concentration between roadside and ambient is not substantially influenced by condensation and evaporation (e.g., Ketzel and Berkowicz, 2004).

It was found that dry deposition and coagulation of particles were generally relevant for PN concentrations on timescales of the neighborhoods. However, as expected, these processes were less relevant in efficient dispersion conditions. The relative relevance of coagulation compared to dry deposition depended on the concentrations of nanometer size particles $(<50 \mathrm{~nm})$.

Coagulation is especially important for the removal of nanoparticles, in this study defined as particles of the sizes $8-25 \mathrm{~nm}$, which accounted for $70 \%$ of the total PN of the mean traffic-related aerosol.

The typical timescale of dry deposition of particles with $8-25 \mathrm{~nm}$ diameter in the urban environment using different deposition schemes was $0.5-3 \mathrm{~h}$. Average dry deposition velocities were in the range of $0.2-0.9 \mathrm{~cm} \mathrm{~s}^{-1}$; similar with the range of $0.6-0.9 \mathrm{~cm} \mathrm{~s}^{-1}$ estimated by Ketzel and Berkowicz (2004). Large differences between the two considered deposition schemes were evident for very rough urban surfaces and for forests. Most of the urban environmental surfaces are rough, and the influence of surface roughness on the dry deposition seems to be pronounced, especially for those particles that are not deposited efficiently by diffusion and inertial processes (Hussein et al., 2012). A future refinement of the parameterization of dry deposition for use in urban models (Eq. (6) should take into account the dependence of the deposition velocity on the underlying urban surface. The lack of measurements of deposition velocities for ultrafine particles to various urban surfaces currently impedes such a refinement. 
A simple parameterization of dry deposition and coagulation for urban air quality models was derived. The parameterization of dry deposition and coagulation can predict total particle number concentrations between roadside and the urban background within an inaccuracy of $\sim 10 \%$, compared to simulations with the fully size-resolved MAFOR model. Inclusion of more PN data from other traffic sites and cities might improve the overall accuracy of the parameterization. Potentially, the process of condensational growth might be included in the framework of the current PN parameterization. However, new particle formation events in the urban background air, frequently associated with a prominent nucleation mode with peak diameter $D_{\mathrm{p}}<10 \mathrm{~nm}$ (Hussein et al., 2014), probably cannot be sufficiently accurately represented by such a simplified parameterization.

Computation of the aerosol evolution between the roadside station and the neighborhood environment involved several assumptions and uncertain parameters. Due to the lack of measurements of the gas-phase and particle phase concentrations of semi-volatile compounds during the studied campaigns, the contributions from condensation and evaporation of condensable vapors emitted with the vehicle exhaust to $\mathrm{PN}$ changes are uncertain. Due to the wide span of measured deposition velocities in literature, the contribution from dry deposition to PN losses has an uncertainty range from -76 to $+64 \%$. The removal of nanoparticles by coagulation is further enhanced when considering the fractal nature of soot aggregates and the combined effect of van der Waals and viscous interactions. Taking into account these effects doubles the contribution of coagulation to PN losses between roadside and neighborhood.

Designing mitigation policies for ultrafine particle pollution in the future will require operational modelling of PN on urban scales. The simplified parameterization we present can be implemented in both Gaussian and Eulerian models. However, it is recommended that such modelling systems are evaluated against measured PN and correlative data in a variety of urban settings.

\section{Code availability}

The computer code of the MAFOR aerosol dynamics model, version 1.8, can be made available upon request (contact: Matthias Karl on email matthias.karl@hzg.de). The code is written in FORTRAN 90.

\section{The Supplement related to this article is available online at doi:10.5194/acp-16-4817-2016-supplement.}

Acknowledgements. This work was funded by the EU Seventh Framework Programme - (ENV.2009. 1.2.2.1) project TRANSPHORM, and the project "Understanding the link between
Air pollution and Distribution of related Health Impacts and Welfare in the Nordic countries" funded by Nordforsk. We thank Leena Kangas (FMI) for extraction of atmospheric stability data for Helsinki campaigns.

The article processing charges for this open-access publication were covered by a Research

Centre of the Helmholtz Association.

Edited by: R. MacKenzie

\section{References}

Asmi, A., Wiedensohler, A., Laj, P., Fjaeraa, A.-M., Sellegri, K., Birmili, W., Weingartner, E., Baltensperger, U., Zdimal, V., Zikova, N., Putaud, J.-P., Marinoni, A., Tunved, P., Hansson, H.C., Fiebig, M., Kivekäs, N., Lihavainen, H., Asmi, E., Ulevicius, V., Aalto, P. P., Swietlicki, E., Kristensson, A., Mihalopoulos, N., Kalivitis, N., Kalapov, I., Kiss, G., de Leeuw, G., Henzing, B., Harrison, R. M., Beddows, D., O’Dowd, C., Jennings, S. G., Flentje, H., Weinhold, K., Meinhardt, F., Ries, L., and Kulmala, M.: Number size distributions and seasonality of submicron particles in Europe 2008-2009, Atmos. Chem. Phys., 11, 5505-5538, doi:10.5194/acp-11-5505-2011, 2011.

Dall'Osto, M., Thorpe, A., Beddows, D. C. S., Harrison, R. M., Barlow, J. F., Dunbar, T., Williams, P. I., and Coe, H.: Remarkable dynamics of nanoparticles in the urban atmosphere, Atmos. Chem. Phys., 11, 6623-6637, doi:10.5194/acp-11-66232011, 2011.

Fridell, E., Steen, E., and Peterson, K.: Primary particles in ship emission, Atmos. Environ., 42, 1160-1168, 2008.

Gidhagen, L., Johansson, C., Langner, J., and Foltescu, V. L.: Urban scale modeling of particle number concentration in Stockholm, Atmos. Environ., 39, 1711-1725, 2005.

Guha, A.: A unified Eulerian theory of turbulent deposition to smooth and rough surfaces, J. Aerosol Sci., 28, 1517-1537, 1997.

Hanna, S. R., Briggs, G. A., and Hosker Jr., R. P.: Handbook on Atmospheric Diffusion, edited by: Smith, J. S., DOE/TIC-11223, Technical Information Center, US Department of Energy, Springfield, USA, 1982.

Harris, S. J. and Maricq, M. M.: Signature size distributions for diesel and gasoline engine exhaust particulate matter, J. Aerosol Sci., 32, 749-764, 2001.

Harrison, R. M., Beddows, D. C. S., and Dall'Osto, M.: PMF analysis of wide-range particle size spectra collected on a major highway, Environ. Sci. Technol., 45, 5522-5528, 2011.

Harrison, R. M., Jones, A. M., Beddows, D. C. S., Dall'Osto, M., and Nikolova, I.: Evaporation of traffic-generated nanoparticles during advection from source, Atmos. Environ., 125, 1-7, doi:10.1016/j.atmosenv.2015.10.077, 2016.

Hussein, T., Kukkonen, J., Korhonen, H., Pohjola, M., Pirjola, L., Wraith, D., Härkönen, J., Teinilä, K., Koponen, I. K., Karppinen, A., Hillamo, R., and Kulmala, M.: Evaluation and modeling of the size fractionated aerosol particle number concentration measurements nearby a major road in Helsinki - Part II: Aerosol measurements within the SAPPHIRE project, Atmos. Chem. Phys., 7, 4081-4094, doi:10.5194/acp-7-4081-2007, 2007. 
Hussein, T., Smolik, J., Kerminen, V.-M., and Kulmala, M.: Modeling dry deposition of aerosol particles onto rough surfaces, Aerosol Sci. Tech., 46, 44-59, 2012.

Hussein, T., Mølgaard, B., Hannuniemi, H., Martikainen, J., Järvi, L., Wegner, T., Ripamonti, G., Weber, S., Vesala, T., and Hämeri, K.: Fingerprints of the urban particle number size distribution in Helsinki, Finland: local versus regional characteristics, Boreal Environ. Res., 19, 1-20, 2014.

Jacobson, M. Z.: Numerical techniques to solve condensational and dissolutional growth equations when growth is coupled to reversible reactions, Aerosol Sci. Tech., 27, 491-498, 1997.

Jacobson, M. Z. and Seinfeld, J. H.: Evolution of nanoparticle size and mixing state near the point of emission, Atmos. Environ., 38, 1839-1850, 2004.

Johansson, C., Norman, M., and Gidhagen, L.: Spatial and temporal variations of $\mathrm{PM}_{10}$ and particle number concentrations in urban air, Environ. Monit. Assess., 127, 477-487, 2007.

Karl, M., Gross, A., Pirjola, L., and Leck, C.: A new flexible multicomponent model for the study of aerosol dynamics in the marine boundary layer, Tellus B, 63, 1001-1025, doi:10.1111/j.16000889.2011.00562.x, 2011.

Karl, M., Dye, C., Schmidbauer, N., Wisthaler, A., Mikoviny, T., D’Anna, B., Müller, M., Borrás, E., Clemente, E., Muñoz, A., Porras, R., Ródenas, M., Vázquez, M., and Brauers, T.: Study of OH-initiated degradation of 2-aminoethanol, Atmos. Chem. Phys., 12, 1881-1901, doi:10.5194/acp-12-1881-2012, 2012.

Kasper, A., Aufdenblatten, S., Forss, A., Mohr, M., and Burtscher, H.: Particulate emissions from a low-speed marine diesel engine, Aerosol Sci. Tech., 41, 24-32, 2007.

Kerminen, V.-M., Pakkanen, T. A., Mäkelä, T., Hillamo, R. E., Rönkkö, T., Virtanen, A., Keskinen, J., Pirjola, L., Hussein, T., and Hämeri, K.: Development of particle number size distribution near a major road in Helsinki during an episodic inversion situation, Atmos. Environ., 41, 1759-1767, 2007.

Ketzel, M. and Berkowicz, R.: Modelling the fate of ultrafine particles from exhaust pipe to rural background: an analysis of time scales for dilution, coagulation and deposition, Atmos. Environ., 38, 2639-2652, 2004.

Ketzel, M. and Berkowicz, R.: Multi-plume aerosol dynamics and transport model for urban scale particle pollution, Atmos. Environ., 39, 3407-3420, 2005.

Keuken, M. P., Henzing, J. S., Zandveld, P., van den Elshout, S., and Karl, M.: Dispersion of particle numbers and elemental carbon from road traffic, a harbor and an airstrip in the Netherlands, Atmos. Environ., 54, 320-327, 2012.

Kittelson, D. B.: Engines and nanoparticles: a review, J. Aerosol Sci., 29, 575-588, 1998.

Kleinman, M. T., Araujo, J. A., Nel, A., Sioutas, C., Campbell, A., Cong, P. Q., Li, H., and Bondy, S. C.: Inhaled ultrafine particulate matter affects CNS inflammatory processes and may act via MAP kinase signaling pathways, Toxicol. Lett., 178, 127-130, doi:10.1016/j.toxlet.2008.03.001, 2008

Kouznetsov, R. and Sofiev, M.: A methodology for evaluation of vertical dispersion and dry deposition of atmospheric aerosol, $\mathrm{J}$. Geophys. Res., 117, D01202, doi:10.1029/2011JD016366, 2012.

Kreyling, W. G., Semmler-Behnke, M., Takenaka, S., and Möller, W.: Differences in the biokinetics of inhaled nano- versus micrometer-sized particles, Accounts Chem. Res., 46, 714-722, doi:10.1021/ar300043r, 2013.
Kukkonen, J., Karl, M., Keuken, M. P., Denier van der Gon, H. A. C., Denby, B. R., Singh, V., Douros, J., Manders, A., Samaras, Z., Moussiopoulos, N., Jonkers, S., Aarnio, M., Karppinen, A., Kangas, L., Lützenkirchen, S., Petäjä, T., Vouitsis, I., and Sokhi, R. S.: Modelling the dispersion of particle numbers in five European cities, Geosci. Model Dev., 9, 451-478, doi:10.5194/gmd-9-4512016, 2016.

Kumar, P., Ketzel, M., Vardoulakis, S., Pirjola, L., and Britter, R.: Dynamics and dispersion modelling of nanoparticles in the urban atmospheric environment - a review, J. Aerosol Sci., 42, 580 603, 2011.

Lemmetty, M., Rönkkö, T., Virtanen, A., Keskinen, J., and Pirjola, L.: The effect of Sulphur in diesel exhaust aerosol: Models compared with measurements, Aerosol Sci. Tech., 42, 916-929, 2008.

Lemmon, E. W. and Goodwin, A. R. H.: Critical properties and vapor pressure equation for alkanes $\mathrm{C}_{n} \mathrm{H}_{2 n+2}$ : normal alkanes and isomers for $n=4$ through $n=9$, J. Phys. Chem. Ref. Data, 29, 1-39, 2000.

Lighty, J. S., Veranth, J. M., and Sarofim, A. F.: Combustion aerosols: factors governing their size and composition and implications to human health, JAPCA J. Air Waste Ma., 50, 15651618, 2000.

Maricq, M. M.: Chemical characterization of particulate emissions from diesel engines: a review, J. Aerosol Sci., 38, 1079-1118, 2007.

Mathis, U., Mohr, M., and Forss, A.-M.: Comprehensive particle characterization of modern gasoline and diesel passenger cars at low ambient temperatures, Atmos. Environ., 39, 107-117, 2005.

Morawska, L., Ristovski, Z., Jayaratne, E. R., Koegh, D. U., and Ling, X.: Ambient nano and ultrafine particles from motor vehicle emissions: characteristics, ambient processing and implications on human exposure, Atmos. Environ., 42, 8113-8138, 2008.

Oberdörster, G., Oberdörster, E., and Oberdörster, J.: Nanotoxicology: an emerging discipline evolving from studies of ultrafine particles, Environ. Health Persp., 113, 823-839, 2005.

Petersen, W. B.: User's Guide for Hiway-2: A Highway Air Pollution Model, US Environmental Protection Agency, EPA-600/880-018, Research Triangle Park, NC, USA, 1980.

Petroff, A., Mailliat, A., Amielh, M., and Anselmet, F.: Aerosol dry deposition on vegetative canopies. Part II: A new modelling approach and applications, Atmos. Environ., 42, 3654-3683, 2008.

Petzold, A., Hasselbach, J., Lauer, P., Baumann, R., Franke, K., Gurk, C., Schlager, H., and Weingartner, E.: Experimental studies on particle emissions from cruising ship, their characteristic properties, transformation and atmospheric lifetime in the marine boundary layer, Atmos. Chem. Phys., 8, 2387-2403, doi:10.5194/acp-8-2387-2008, 2008.

Pey, J., Querol, X., Alastuey, A., Rodriguez, S., Putaud, J.-P., and Van Dingenen, R.: Source apportionment of urban fine and ultra fine particle number concentration in a Western Mediterranean city, Atmos. Environ., 43, 4407-4415, 2009.

Pirjola, L. and Kulmala, M.: Development of particle size and composition distributions with a novel aerosol dynamics model, Tellus B, 53, 491-509, 2001.

Pirjola, L., Tsyro, S., Tarrason, L., and Kulmala, M.: A monodisperse aerosol dynamics module - a promising candidate for use 
in the Eulerian long-range transport model, J. Geophys. Res., 108, 4258, doi:10.1029/2002JD002867, 2003.

Pirjola, L., Parviainen, H., Hussein, T., Valli, A., Hämeri, K., Aalto, P., Virtanen, A., Keskinen, J., Pakkanen, T., Mäkelä, T., and Hillamo, R.: "Sniffer" - a novel tool for chasing vehicles and measuring traffic pollutants, Atmos. Environ., 38, 3625-3635, 2004.

Pirjola, L., Paasonen, P., Pfeiffer, D., Hussein, T., Hämeri, K., Koskentalo, T., Virtanen, A., Rönkkö, T., Keskinen, J., Pakkanen, T. A., and Hillamo, R. E.: Dispersion of particles and trace gases nearby a city highway: mobile laboratory measurements in Finland, Atmos. Environ., 40, 867-879, 2006.

Pirjola, L., Lähde, T., Niemi, J. V., Kousa, A., Rönkkö, T., Karjalainen, P., Keskinen, J., Frey, A., and Hillamo, R.: Spatial and temporal characterization of traffic emission in urban microenvironments with a mobile laboratory, Atmos. Environ., 63, 156167, 2012.

Pirjola, L., Pajunoja, A., Walden, J., Jalkanen, J.-P., Rönkkö, T., Kousa, A., and Koskentalo, T.: Mobile measurements of ship emissions in two harbour areas in Finland, Atmos. Meas. Tech., 7, 149-161, doi:10.5194/amt-7-149-2014, 2014.

Pohjola, M. A., Pirjola, L., Kukkonen, J., and Kulmala, M.: Modelling of the influence of aerosol processes for the dispersion of vehicular exhaust plumes in street environment, Atmos. Environ., 37, 339-351, 2003.

Pohjola, M. A., Pirjola, L., Karppinen, A., Härkönen, J., Korhonen, H., Hussein, T., Ketzel, M., and Kukkonen, J.: Evaluation and modelling of the size fractionated aerosol particle number concentration measurements nearby a major road in Helsinki - Part I: Modelling results within the LIPIKA project, Atmos. Chem. Phys., 7, 4065-4080, doi:10.5194/acp-7-4065-2007, 2007.

Pryor, S.: Size-resolved particle deposition velocities of sub-100 nm diameter particles over a forest, Atmos. Environ., 40, 6192-6200, 2006

Rao, K. S., Gunter, R. L., White, J. R., and Hosker, R. P.: Turbulence and dispersion modeling near highways, Atmos. Environ., 36, 4337-4346, 2002.

Reinap, A., Wiman, B., Svenningsson, B., and Gunnarsson, S.: Oak leaves as aerosol collectors: relationships with wind velocity and particle size distribution, experimental results and their implications, Trees-Struct. Funct., 23, 1263-1274, doi:10.1007/s00468009-0366-4, 2009.
Ristovski, Z., Jayaratne, E. R., Lim, M., Ayoko, G. A., and Morawska, L.: Influence of diesel fuel sulphur on the nanoparticle emissions from city buses, Environ. Sci. Technol., 40, 13141320, 2006.

Rönkkö, T., Virtanen, A., Kannosto, J., Keskinen, J., Lappi, M., and Pirjola, L.: Nucleation mode particles with a non-volatile core in the exhaust of a heavy duty diesel vehicle, Environ. Sci. Technol. 41, 6384-6389, doi:10.1021/es0705339, 2007.

Schack Jr., C. J., Pratsinis, S. E., and Friedlander, S. K.: A general correlation for deposition of suspended particles from turbulent gases to completely rough surfaces, Atmos. Environ., 19, 953 960, doi:10.1016/0004-6981(85)90240-9, 1985.

Slørdal, L. H., Solberg, S., and Walker, S. E.: The Urban Air Dispersion Model EPISODE applied in AirQUIS 2003, Technical description, Norwegian Institute for Air Research, NILU TR 12/03, Kjeller, Norway, 2003.

Soares, J., Kousa, A., Kukkonen, J., Matilainen, L., Kangas, L., Kauhaniemi, M., Riikonen, K., Jalkanen, J.-P., Rasila, T., Hänninen, O., Koskentalo, T., Aarnio, M., Hendriks, C., and Karppinen, A.: Refinement of a model for evaluating the population exposure in an urban area, Geosci. Model Dev., 7, 1855-1872, doi:10.5194/gmd-7-1855-2014, 2014.

Vignati, E., Berkowicz, R., Palmgren, F., Lyck, E., and Hummelshoj, P.: Transformation of size distributions of emitted particles in streets, Sci. Total Environ., 235, 37-49, 1999.

Virtanen, A., Ristimäki, J., Marjamäki, M., Vaaraslahti, K., Keskinen, J., and Lappi, M.: Effective density of diesel exhaust particles as a function of size, SAE Technical Papers Series 2002-010056, SAE 2002 World Congress and Exhibition, Detroit, MI, USA, 2002.

Zhang, K. M. and Wexler, A. S.: Evolution of particle number distribution near roadways - Part I: Analysis of aerosol dynamics and its implications for engine emission measurement, Atmos. Environ., 38, 6643-6653, 2004.

Zhang, K. M., Wexler, A. S., Zhu, Y. F., Hinds, W. C., and Sioutas, C.: Evolution of particle number distribution near roadways. Part II: The "road-to-ambient" process, Atmos. Environ., 38, 6655-6665, 2004. 